\title{
Paracetamol for low back pain (Review)
}

Saragiotto BT, Machado GC, Ferreira ML, Pinheiro MB, Abdel Shaheed C, Maher CG

Saragiotto BT, Machado GC, Ferreira ML, Pinheiro MB, Abdel Shaheed C, Maher CG.

Paracetamol for low back pain.

Cochrane Database of Systematic Reviews 2016, Issue 6. Art. No.: CD012230.

DOI: 10.1002/14651858.CD012230.

www.cochranelibrary.com 
TABLE OF CONTENTS

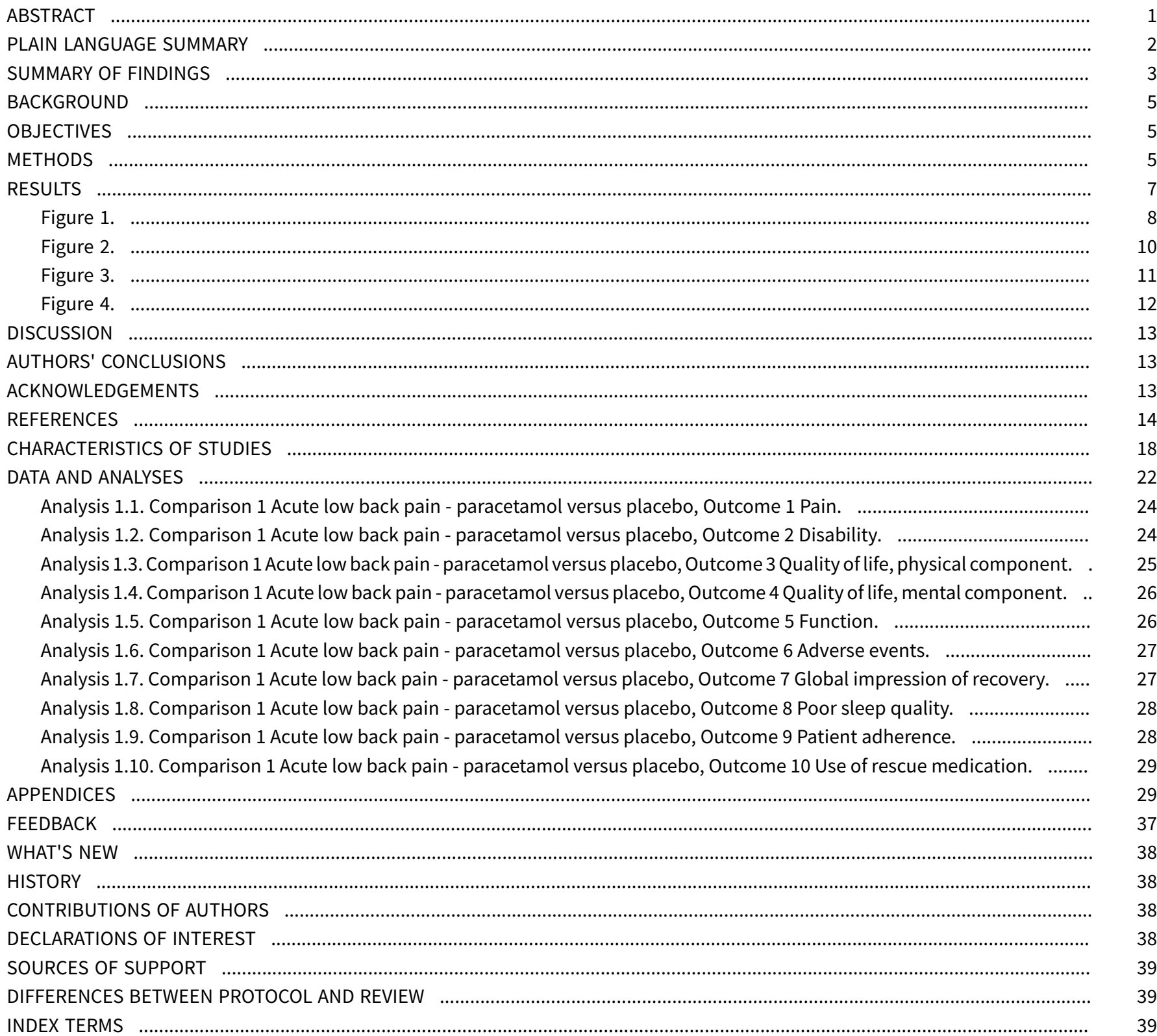


[Intervention Review]

\section{Paracetamol for low back pain}

Bruno T Saragiotto ${ }^{1}$, Gustavo C Machado², Manuela L Ferreira 3 , Marina B Pinheiro 4 , Christina Abdel Shaheed 5 , Christopher G Maher6

1Masters and Doctoral Programs in Physical Therapy, Universidade Cidade de São Paulo, Sao Paulo, Brazil. 2Sydney School of Public Health, Sydney Medical School, The University of Sydney, Sydney, Australia. 3Institute of Bone and Joint Research, The Kolling Institute, Sydney Medical School, The University of Sydney, Sydney, Australia. ${ }^{4}$ Discipline of Physiotherapy, Faculty of Health Sciences, The University of Sydney, Sydney, Australia. ${ }^{5}$ The George Institute for Global Health, Sydney, Australia. ${ }^{6}$ Sydney School of Public Health, University of Sydney, Sydney, Australia

Contact: Bruno T Saragiotto, Masters and Doctoral Programs in Physical Therapy, Universidade Cidade de São Paulo, Sao Paulo, Brazil. bruno.saragiotto@gmail.com.

Editorial group: Cochrane Back and Neck Group.

Publication status and date: Edited (no change to conclusions), comment added to review, published in Issue 1, 2019.

Citation: Saragiotto BT, Machado GC, Ferreira ML, Pinheiro MB, Abdel Shaheed C, Maher CG. Paracetamol for low back pain. Cochrane Database of Systematic Reviews 2016, Issue 6. Art. No.: CD012230. DOI: 10.1002/14651858.CD012230.

Copyright ( 2019 The Cochrane Collaboration. Published by John Wiley \& Sons, Ltd.

\section{A B S T R A C T}

\section{Background}

Analgesic medication is the most frequently prescribed treatment for low back pain (LBP), of which paracetamol (acetaminophen) is recommended as the first choice medication. However, there is uncertainty about the efficacy of paracetamol for LBP.

\section{Objectives}

To investigate the efficacy and safety of paracetamol for non-specific LBP.

\section{Search methods}

We conducted searches on the Cochrane Central Register of Controlled Trials (CENTRAL, which includes the Back and Neck Review Group trials register), MEDLINE, EMBASE, CINAHL, AMED, Web of Science, LILACS, and IPA from their inception to 7 August 2015. We also searched the reference lists of eligible papers and trial registry websites (WHO ICTRP and ClinicalTrials.gov).

\section{Selection criteria}

We only considered randomised trials comparing the efficacy of paracetamol with placebo for non-specific LBP. The primary outcomes were pain and disability. We also investigated quality of life, function, adverse effects, global impression of recovery, sleep quality, patient adherence, and use of rescue medication as secondary outcomes.

\section{Data collection and analysis}

Two review authors independently performed the data extraction and assessed risk of bias in the included studies. We also evaluated the quality of evidence using the GRADE approach. We converted scales for pain intensity to a common 0 to 100 scale. We quantified treatment effects using mean difference for continuous outcomes and risk ratios for dichotomous outcomes. We used effect sizes and $95 \%$ confidence intervals as a measure of treatment effect for the primary outcomes. When the treatment effects were smaller than 9 points on a 0 to 100 scale, we considered the effect as small and not clinically important.

\section{Main results}

Our searches retrieved 4449 records, of which two trials were included in the review $(n=1785)$. For acute LBP, there is high-quality evidence for no difference between paracetamol ( $4 \mathrm{~g}$ per day) and placebo at 1 week (immediate term), 2 weeks, 4 weeks, and 12 weeks (short term) for the primary outcomes. There is high-quality evidence that paracetamol has no effect on quality of life, function, global impression of 
recovery, and sleep quality for all included time periods. There were also no significant differences between paracetamol and placebo for adverse events, patient adherence, or use of rescue medication. No trials were identified evaluating patients with subacute or chronic LBP.

\section{Authors' conclusions}

We found that paracetamol does not produce better outcomes than placebo for people with acute LBP.

\section{PLAIN LANGUAGE SUMMARY}

\section{Paracetamol for low back pain}

\section{Review question}

To see how well paracetamol works for non-specific low back pain (LBP). Non-specific LBP is back pain for which there is no identified disease or condition.

\section{Background}

Paracetamol is one of the most commonly prescribed medicines for people with LBP, and it is recommended in the guidelines that are issued to help doctors manage different illnesses. However, recent evidence has called into question how effective it is.

\section{Search date}

The evidence is current to August 2015.

\section{Study characteristics}

We included two trials with a total of 1785 participants in this review with participants whose back pain occurred suddenly and recently (acute). Most of the people in the study (90\%) were middle-aged and came from a single trial that looked at acute back pain. Both trials tested paracetamol against a placebo (which contains nothing that could act as a medicine). Participants were followed between one day and 12 weeks. The main outcomes we studied were pain and disability; we also looked at quality of life, how easily people could go about their daily lives, unpleasant or unwanted side effects, how well people felt they had recovered, sleep quality, whether participants had taken the medicine as prescribed, and if it had been necessary to take 'rescue medication' because the paracetamol had not worked. We combined the findings from one trial $(n=1651)$ into a single analysis (meta-analysis) that compared paracetamol to a placebo; the second trial did not report the results for the placebo, and so it could not be included.

\section{Key results and quality of evidence}

We found high-quality evidence that paracetamol ( $4 \mathrm{~g}$ per day) is no better than placebo for relieving acute LBP in either the short or longer term. It also worked no better than placebo on the other aspects studied, such as quality of life and sleep quality. About one in five people reported side effects, though few were serious, and there was no difference between intervention and control groups. As most of the participants studied were middle-aged, we cannot be sure that the findings would be the same for other age groups. 
SUMMARY OF FINDINGS

Summary of findings for the main comparison. Paracetamol compared with placebo for acute low back pain

Paracetamol compared with placebo for acute low back pain

Patient or population: People with acute low back pain

Settings: Primary care

Intervention: Paracetamol

Comparison: Placebo

\begin{tabular}{|c|c|c|c|c|c|c|}
\hline \multirow[t]{3}{*}{ Outcomes } & \multicolumn{2}{|c|}{ Illustrative comparative risks ${ }^{\star}(95 \% \mathrm{Cl})$} & \multirow{3}{*}{$\begin{array}{l}\text { Relative effect } \\
(95 \% \mathrm{Cl})\end{array}$} & \multirow{3}{*}{$\begin{array}{l}\text { No of partici- } \\
\text { pants } \\
\text { (studies) }\end{array}$} & \multirow{3}{*}{$\begin{array}{l}\text { Quality of the } \\
\text { evidence } \\
\text { (GRADE) }\end{array}$} & \multirow[t]{3}{*}{ Comments } \\
\hline & Assumed risk & Corresponding risk & & & & \\
\hline & Placebo & Paracetamol & & & & \\
\hline $\begin{array}{l}\text { Pain } \\
1 \text { week (immediate } \\
\text { term) } \\
\text { (NRS } 0 \text { to } 100 \text { ) }\end{array}$ & $\begin{array}{l}\text { The mean pain in } \\
\text { the control group } \\
\text { was } \\
36 \text { points }\end{array}$ & $\begin{array}{l}\text { The mean pain in the intervention } \\
\text { group was } \\
\mathbf{1 . 4 9} \text { higher } \\
\text { (1.30 lower to } 4.28 \text { higher) }\end{array}$ & - & $\begin{array}{l}1520 \\
\text { (1 study) }\end{array}$ & $\begin{array}{l}\oplus \oplus \oplus \oplus \\
\text { high }\end{array}$ & $\begin{array}{l}\text { The difference is not statisti- } \\
\text { cally } \\
\text { or clinically significant }\end{array}$ \\
\hline $\begin{array}{l}\text { Pain } \\
12 \text { weeks (short } \\
\text { term) } \\
\text { (NRS } 0 \text { to } 100 \text { ) }\end{array}$ & $\begin{array}{l}\text { The mean pain in } \\
\text { the control group } \\
\text { was } \\
13 \text { points }\end{array}$ & $\begin{array}{l}\text { The mean pain in the intervention } \\
\text { group was } \\
\mathbf{0 . 5 0} \text { lower } \\
\text { ( } 2.92 \text { lower to } 1.92 \text { higher) }\end{array}$ & - & $\begin{array}{l}1526 \\
\text { (1 study) }\end{array}$ & $\begin{array}{l}\oplus \oplus \oplus \oplus \\
\text { high }\end{array}$ & $\begin{array}{l}\text { The difference is not statisti- } \\
\text { cally } \\
\text { or clinically significant }\end{array}$ \\
\hline $\begin{array}{l}\text { Disability } \\
12 \text { weeks (short } \\
\text { term) }\end{array}$ & $\begin{array}{l}\text { The mean disabil- } \\
\text { ity in the control } \\
\text { group was }\end{array}$ & $\begin{array}{l}\text { The mean disability in the interven- } \\
\text { tion group was } \\
\mathbf{0 . 1 0} \text { higher }\end{array}$ & - & $\begin{array}{l}1522 \\
\text { (1 study) }\end{array}$ & $\begin{array}{l}\oplus \oplus \oplus \oplus \\
\text { high }\end{array}$ & $\begin{array}{l}\text { The difference is not statisti- } \\
\text { cally } \\
\text { or clinically significant }\end{array}$ \\
\hline
\end{tabular}

2.4 points (0.39 lower to 0.59 higher)


(RMDQ 0 to 24)

Any adverse events

107 per 1000

115 per 1000

R 1.07

1624

$\oplus \oplus \oplus \oplus$

The difference is not statisti-

Up to 12 weeks' fol-

(92 to 142$)$

(0.86 to 1.33 )

(1 study)

high

low-up

Serious adverse

90 per 1000

81 per 1000

(27 to 240 )

RR 0.90

1643

(1 study)

$\oplus \oplus \oplus$

(0.30 to 2.67$)$

moderate $^{1}$

cally

\section{Up to 12 weeks' fol-}

low-up

${ }^{*}$ The corresponding risk (and its $95 \%$ confidence interval) is based on the assumed risk in the comparison group and the relative effect of the intervention (and its $95 \%$ $\mathrm{Cl})$.

Cl: confidence interval; NRS: Numeric Rating Scale; RMDQ: Roland Morris Disability Questionnaire; RR: risk ratio

GRADE Working Group grades of evidence

High quality: Further research is very unlikely to change our confidence in the estimate of effect.

Moderate quality: Further research is likely to have an important impact on our confidence in the estimate of effect and may change the estimate.

Low quality: Further research is very likely to have an important impact on our confidence in the estimate of effect and is likely to change the estimate.

Very low quality: We are very uncertain about the estimate.

1. Downgraded for imprecision. 


\section{B A C K G R O U N D}

Low back pain (LBP) is the leading cause of disability worldwide (Global Burden of Disease Study 2015). Patients usually experience a substantial reduction in pain intensity in the first six weeks following the onset of a new episode, however in many patients the pain does not resolve completely (Menezes 2012; Pengel 2003). About $40 \%$ of patients will develop chronic LBP, persisting for months or years (Menezes 2009). Even for those patients who recover quickly from the initial acute episode, a recurrent episode during the following 12 months is very common (Henschke 2008).

The most frequently prescribed treatment for back pain is an analgesic medication; according to clinical practice guidelines, paracetamol should be the first-choice pain medicine for people with non-specific LBP, especially in the acute phase (Koes 2010). However, the guideline recommendations for prescribing paracetamol are based on indirect evidence of efficacy from studies outside the LBP field, consensus among the guideline development group, and greater safety compared to alternative pain medicines (for example non-steroidal anti-inflammatory drugs (NSAIDs) or opioids) (van Tulder 2006). The uncertainty about the efficacy of paracetamol as an analgesic for LBP was highlighted in the first systematic review of paracetamol for LBP, which noted the absence of robust data on treatment efficacy (Davies 2008). Subsequent to the Davies 2008 review, the PACE trial has called into question the efficacy of paracetamol for people with acute LBP (Williams 2014).

The PACE trial enrolled 1652 participants and reported no significant difference in days to recovery between participants taking paracetamol in a time-contingent fashion, taking paracetamol as required, or placebo for acute LBP (Williams 2014). There was also no effect for any of the secondary outcomes (for example pain intensity, disability, function, global rating of symptom change, sleep quality, and quality of life). The presumed efficacy of paracetamol for LBP as reflected in guideline endorsement is thus controversial, and a Cochrane review of placebo-controlled trials could provide the credible evidence needed to inform decision-making based on the highest standard of evidence.

This review is an update of a recent systematic review on paracetamol for spinal pain or osteoarthritis (Machado 2015). The Machado 2015 review has been split into two Cochrane reviews, one focusing on knee or hip osteoarthritis, and this one, which focuses on non-specific LBP. Both reviews follow the same methodology according to the guidelines of The Cochrane Collaboration, Higgins 2011, and the Cochrane Back and Neck Review Group, Furlan 2015.

\section{Description of the condition}

LBP can be defined as pain or discomfort below the ribs and above the gluteal crease, with or without referred leg pain (Airaksinen 2006). The great majority of people with LBP are classified as having non-specific LBP, which is defined as LBP without any known specific cause or pathology, such as nerve root compromise or serious spinal pathology (for example fracture, cancer, infection, or inflammatory diseases). This condition is also staged according to the duration of symptoms: acute LBP is an episode persisting for less than six weeks; subacute LBP with symptoms persisting between six and 12 weeks; and chronic LBP when symptoms persists for 12 weeks or longer (Furlan 2015).

\section{Description of the intervention}

Paracetamol (acetaminophen) is one of the most widely used nonprescription medicines in the world. It has been commercially available for over 60 years, making it one of the oldest analgesics on the market (Jozwiak-Bebenista 2014). The usual adult recommended dose is $325 \mathrm{mg}$ to $1000 \mathrm{mg}$ every four or six hours, not exceeding $1000 \mathrm{mg}$ per dose or $4000 \mathrm{mg}$ per day (Amar 2007). It can be prescribed alone or in combination with other medicines, such as an NSAID or opioid. Paracetamol has been promoted as the preferred medication for people with LBP due to its low risk of side effects and similar action to other analgesics (that is, NSAIDs) (Graham 2013; Koes 2010).

\section{How the intervention might work}

Although paracetamol has been widely used in medical practice, its mechanism of action remains uncertain (Graham 2013). The main proposed mechanism is the inhibition of cyclooxygenase (COX) enzymes through metabolism by the peroxidase function of these isoenzymes. This process results in inhibition of phenoxyl radical formation from a critical tyrosine residue important for the cyclooxygenase activity of COX-1 and COX-2 and prostaglandin synthesis (Graham 2013; Jozwiak-Bebenista 2014). Paracetamol is a preferential inhibitor of COX-2 due to its gastrointestinal tolerance and poor inhibition of platelet activity (Graham 2013; Hinz 2008; Hinz 2012). In addition, recent evidence suggests that the analgesic action of paracetamol is mediated by inhibition of COX-3 (Botting 2005).

Paracetamol is widely considered to be a safe drug when administered in appropriate doses (Jozwiak-Bebenista 2014); however, there is clear evidence that higher doses or prolonged use of paracetamol can lead to liver failure (where the paracetamol compounds are metabolised), cardiovascular events and even death (Graham 2013; Chan 2006; Forman 2005; Roberts 2015; Daly 2008; Sheen 2002).

\section{Why it is important to do this review}

This review is an update of a recent systematic review on paracetamol for spinal pain and osteoarthritis (Machado 2015), which was published in the BMJ. The Cochrane format will allow us to provide a more comprehensive overview of the results and methods than is possible with a journal article. We will also take the opportunity to update the search and focus specifically on LBP.

\section{OB JECTIVES}

To investigate the efficacy and safety of paracetamol for nonspecific LBP.

\section{METHODS}

\section{Criteria for considering studies for this review}

\section{Types of studies}

We only considered placebo-controlled randomised trials. We did not include trials with quasi-random allocation procedures in order to avoid biased estimates of treatment effects across the included studies (Furlan 2015; Higgins 2011).

\section{Types of participants}

Inclusion criteria: 
- People with non-specific acute, subacute, or chronic nonspecific LBP

- People recruited from primary, secondary, or tertiary care

Exclusion criteria:

- People with serious spinal pathology (e.g. cancer, fractures, cauda equina syndrome, and inflammatory diseases)

- Pregnancy

\section{Types of interventions}

We included any dosing regimen of paracetamol compared to placebo. We did not include any combination of medicines with paracetamol. We also excluded the use of paracetamol for postoperative analgesia.

\section{Types of outcome measures}

\section{Primary outcomes}

- Pain intensity

- Disability

\section{Secondary outcomes}

- Quality of life

- Function

- Adverse effects

- Global impression of recovery

- Sleep quality

- Patient adherence

- Use of rescue medication

\section{Search methods for identification of studies}

\section{Electronic searches}

We performed a computerised electronic search to identify relevant articles in the following databases from their inception to 7 August 2015 without language restrictions:

- Cochrane Central Register of Controlled Trials (CENTRAL, which includes the Back and Neck review Group trials register; OvidSP, 1991 to August 2015).

- MEDLINE (OvidSP, 1946 to August Week 12015$)$

- MEDLINE In-Process \& Other Non-Indexed Citations (OvidSP, 7 August 2015).

- EMBASE (Embase.com, 1947 to August 2015).

- Cumulative Index to Nursing and Allied Health Literature (CINAHL) (EBSCO, 1982 to August 2015).

- Allied and Complementary Medicine (AMED) (OvidSP, 1985 to August 2015).

- Web of Science (Thomson Reuters, 1900 to August 2015).

- Latin American and Caribbean Health Sciences Literature (LILACS).

- International Pharmaceutical Abstracts (IPA) (OvidSP, 1970 to August 2015).

The search strategy for each database is presented in the following appendices: Appendix 1; Appendix 2; Appendix 3; Appendix 4; Appendix 5; Appendix 6; Appendix 7; Appendix 8.

\section{Searching other resources}

We also searched the reference lists of eligible papers and the following trial registry websites: World Health Organization (WHO) International Clinical Trials Registry Platform (ICTRP) and ClinicalTrials.gov. The search strategy used for searching other resources is presented in Appendix 9.

\section{Data collection and analysis}

\section{Selection of studies}

Two review authors independently screened titles, abstracts, and full-text papers for potentially eligible studies, resolving any disagreements through discussion or arbitration of a third review author if consensus could not be reached.

\section{Data extraction and management}

Two review authors independently extracted the following data from each included trial using a standardised data extraction form. Disagreements were resolved through discussion or arbitration of a third review author when consensus could not be reached.

- Bibliometric data (authors, year of publication, language).

- Study characteristics (study design, sample size, description of the sample, country, funding).

- Characteristics of the participants (gender, age, duration of symptoms).

- Duration of follow-up assessments.

- Means, standard deviations, and sample sizes for continuous outcome measures. The treatment estimates were extracted in the following hierarchical order: between-group differences, within-group change scores, and follow-up values.

- Number of cases and the total sample size for dichotomous outcomes. For adverse events, we considered the number of participants reporting any adverse event, the number of participants reporting any serious adverse event (as defined by each study), the number of participants withdrawn from study due to adverse events, and the number of participants with abnormal results on liver function tests (hepatic enzyme activity $\geq 1.5$ times the upper limit of the reference range).

\section{Assessment of risk of bias in included studies}

Two review authors independently assessed risk of bias of the included studies. Disagreements were resolved through discussion or arbitration of a third review author when consensus could not be reached. We assessed risk of bias using the 'Risk of bias' assessment tool recommended by The Cochrane Collaboration (Higgins 2011) (Appendix 10). We scored each item as 'high', 'low', or 'unclear' risk of bias.

\section{Measures of treatment effect}

When more than one scale for measuring pain intensity or disability was used, we extracted the more severe estimate reported at baseline. We converted scales for pain intensity to a common 0 (no pain) to 100 (worse pain) scale. We quantified the treatment effects with the mean difference for continuous outcomes, and calculated the risk ratios for the positive outcome for dichotomous outcomes. We used effect sizes and $95 \%$ confidence intervals as a measure of treatment effect. In the previous version of this review (Machado 2015), we considered the minimal clinically important difference (MCID) as 9 points on a 0 to 100 scale based upon the practice in the 
osteoarthritis field (Wandel 2010), though we understand that in the back pain field the MCID is usually considered to be larger than this value (Ostelo 2008). When the treatment effects were smaller than 9 points, we considered the effect as small and not clinically important.

\section{Unit of analysis issues}

To deal with repeated observations on participants, we followed the advocated strategy of defining the outcomes as well as the time points a priori (Higgins 2011). We have previously defined the time points as: immediate term ( $\leq 2$ weeks), short term ( $>2$ weeks but $\leq 3$ months), intermediate term ( $>3$ months but $\leq 12$ months), and long term (> 12 months). However, to account for studies that reported multiple time points within each category, we included all time points reported in the included trials.

\section{Dealing with missing data}

We contacted authors to provide further information when the data reported in the paper was insufficient. When authors were unavailable, we estimated data using the recommendations of The Cochrane Collaboration (Higgins 2011).

\section{Assessment of heterogeneity}

The assessment of heterogeneity was based upon visual inspections of the forest plots looking at the overlap of the confidence intervals, and by the $\mathrm{Chi}^{2}$ test and the $\mathrm{I}^{2}$ statistic as recommended in the Cochrane Handbook for Systematic Reviews of Interventions (Higgins 2011). If substantial heterogeneity was present ( 12 greater than $50 \%$ ), or when we identified clear heterogeneity by visual inspection, we used a random-effects model to combine results and downgraded for inconsistency in the quality of evidence assessment (GRADE).

\section{Assessment of reporting biases}

We did not assess publication bias with funnel plots because too few studies were included in the review. We added no language restriction to our search strategy in order to avoid potential language bias.

\section{Data synthesis}

We assessed the overall quality of the evidence for each outcome using the GRADE approach as recommended in the Cochrane Handbook for Systematic Reviews of Interventions (Higgins 2011), and adapted in the updated Cochrane Back and Neck Review Group method guidelines (Furlan 2015) (Appendix 11). We downgraded the quality of the evidence by one level according to the following criteria: limitation of study design and risk of bias (downgraded if more than a quarter of the participants were from studies with a high risk of bias, that is one or more bias domains judged as high risk), inconsistency of results (downgraded if significant heterogeneity was present by visual inspection or if the 12 value was greater than 50\%), imprecision (downgraded if the upper or lower limits of the $95 \%$ confidence interval crossed the MCID of 9 points (range 0 to 100) (Guyatt 2011), and publication bias (assessed by visual inspection of funnel plots and using Egger's test to investigate publication bias (small-study effects)) (Egger 1997). If the Egger's test result was significant (two-tailed $P<0.1$ ), we would downgrade the quality of evidence (GRADE) by one level for all meta-analyses (Guyatt 2011b). We did not consider the indirectness criterion in this review because we included a specific population with relevant outcomes and direct comparisons (Guyatt 2011a).

We interpreted the overall quality of evidence using the following GRADE descriptors (Furlan 2015):

- High-quality evidence: Further research is very unlikely to change confidence in estimate of effect.

- Moderate-quality evidence: Further research is likely to have an important impact on confidence in estimate of effect and may change the estimate.

- Low-quality evidence: Further research is very likely to have an important impact on confidence in estimate of effect and is likely to change the estimate.

- Very low-quality evidence: Very little confidence in the effect estimate.

- No evidence: We identified no randomised controlled trials that addressed this outcome.

\section{Subgroup analysis and investigation of heterogeneity}

We stratified the analyses based upon the duration of follow-up reported for each outcome (that is, immediate term, short term, intermediate term, and long term).

\section{Sensitivity analysis}

We did not propose any sensitivity analyses as we expected the number of available trials to be low.

\section{RES U L T S}

\section{Description of studies}

See: Characteristics of included studies; Characteristics of excluded studies.

\section{Results of the search}

The search yielded 4449 records, of which two trials fulfilled the inclusion criteria and were included in the review (Figure 1). An additional search for ongoing or registered trials in ClinicalTrials.gov and the WHO ICTRP retrieved 44 records, of which 9 records included paracetamol as an intervention. One record was from a study already included in this review (Williams 2014); we have described the other eight under Excluded studies. 
Figure 1. Study flow diagram.

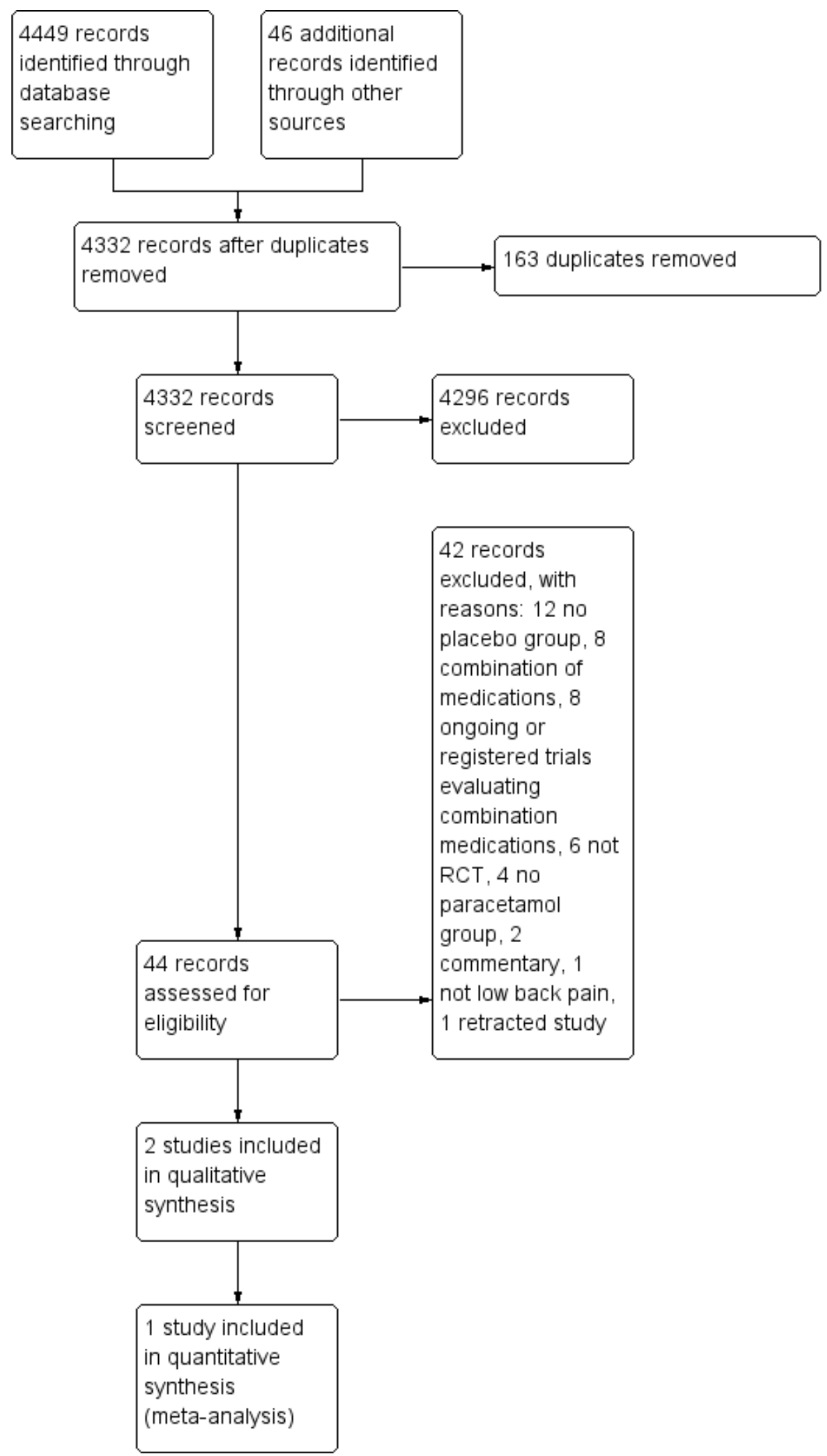




\section{Included studies}

We have included two trials in this review (Nadler 2002; Williams 2014), with a total sample size of 1785 participants (133 and 1653 participants, respectively). We did not include one trial in the metaanalysis as it did not report results for the placebo group, and all attempts to contact the authors and the pharmaceutical company that funded the study were unsuccessful (Nadler 2002).

The trials were conducted in Australia (Williams 2014) and the United States (Nadler 2002). Both trials included people with acute LBP (Nadler 2002; Williams 2014). The trials included 934 men and 842 women, most of whom were middle-aged (mean: 44.2, standard deviation: 13.6), recruited from primary care. The duration of the treatments was two consecutive days (Nadler 2002) and daily until recovered, up to a maximum of four weeks (Williams 2014).

Both trials included single-ingredient paracetamol formulations. In one trial (Nadler 2002), participants took $1 \mathrm{~g}$ of paracetamol tablets four times per day for two days. In the PACE trial (Williams 2014), participants in the time-contingent group took paracetamol tablets $4 \mathrm{~g}$ per day in three divided doses, and those in the 'as required' group took up to $4 \mathrm{~g}$ per day; both groups were asked to take the paracetamol until recovery up to a maximum of four weeks. We included all three PACE trial groups in the meta-analyses, following the recommendations of The Cochrane Collaboration (Higgins 2011).

Regarding the primary outcomes, pain intensity was measured on a 0 to 10 scale in one trial (Williams 2014), and a 0 to 5 scale in one trial (Nadler 2002). Disability was measured using the Roland Morris Disability Questionnaire (RMDQ) from 0 to 24 points in all included trials. Williams 2014 also measured quality of life with the 12-Item Short Form Health Survey (SF-12), and function using the Patient-Specific Functional Scale from 0 to 10. For the secondary outcomes, both trials measured adverse events (Nadler
2002; Williams 2014), and one trial measured adherence to the treatment, use of rescue medication, global impression of recovery (Global Perceived Effect scale from -5 to +5 ), and quality of sleep (number of participants reporting poor sleep quality) (Williams 2014). The rescue medication provided in Williams 2014 was two days' supply of naproxen $250 \mathrm{mg}$ ( 2 tablets initially, and then 1 tablet every 6 to 8 hours as required).

\section{Excluded studies}

We excluded a total of 42 full-text articles assessed for eligibility. Twelve records did not have a placebo group (Cabane 1996; Childers 2005; Corts Giner 1989; Hackett 1988; Hingorani 1971; Jiang 2008; Kuntz 1996; Lee 2008; Madhusudhan 2013; McGuinness 1969; Muller 2005; Tervo 1976); eight used a combination of medications for the intervention group (Borenstein 2001; Codding 2008; Garcia Filho 2006; Gimbel 2001; Muller 1998; Peloso 2004; Ruoff 2003; Schiphorst Preuper 2014); six were not randomised controlled trials (De Almeida Coimbra 1980; Derby 2012; Gammaitoni 2003; Larsen 2012; Miller 2012; Moore 2010); four did not have a paracetamol group (Martinez-Elizondo 1979; Matsushita 2012; Pallay 2004; Yarlas 2013); two were commentaries (Diener 2008; Diener 2008a); one did not include people with LBP (Temple 2007); and one trial has been retracted (Wetzel 2014). The search for ongoing or registered trials retrieved eight potentially eligible records that included paracetamol as an intervention. Seven records used a combination of paracetamol and other medications (NCT00210561; NCT00643383; NCT00736853; NCT01112267; NCT01587274; NCT01776515; NCT01843660), and one record did not have a placebo group (NCT01422291).

\section{Risk of bias in included studies}

The results from the 'Risk of bias' assessment for the individual studies are summarised in Figure 2. 
Figure 2. Risk of bias summary: review authors' judgements about each risk of bias item for each included study.

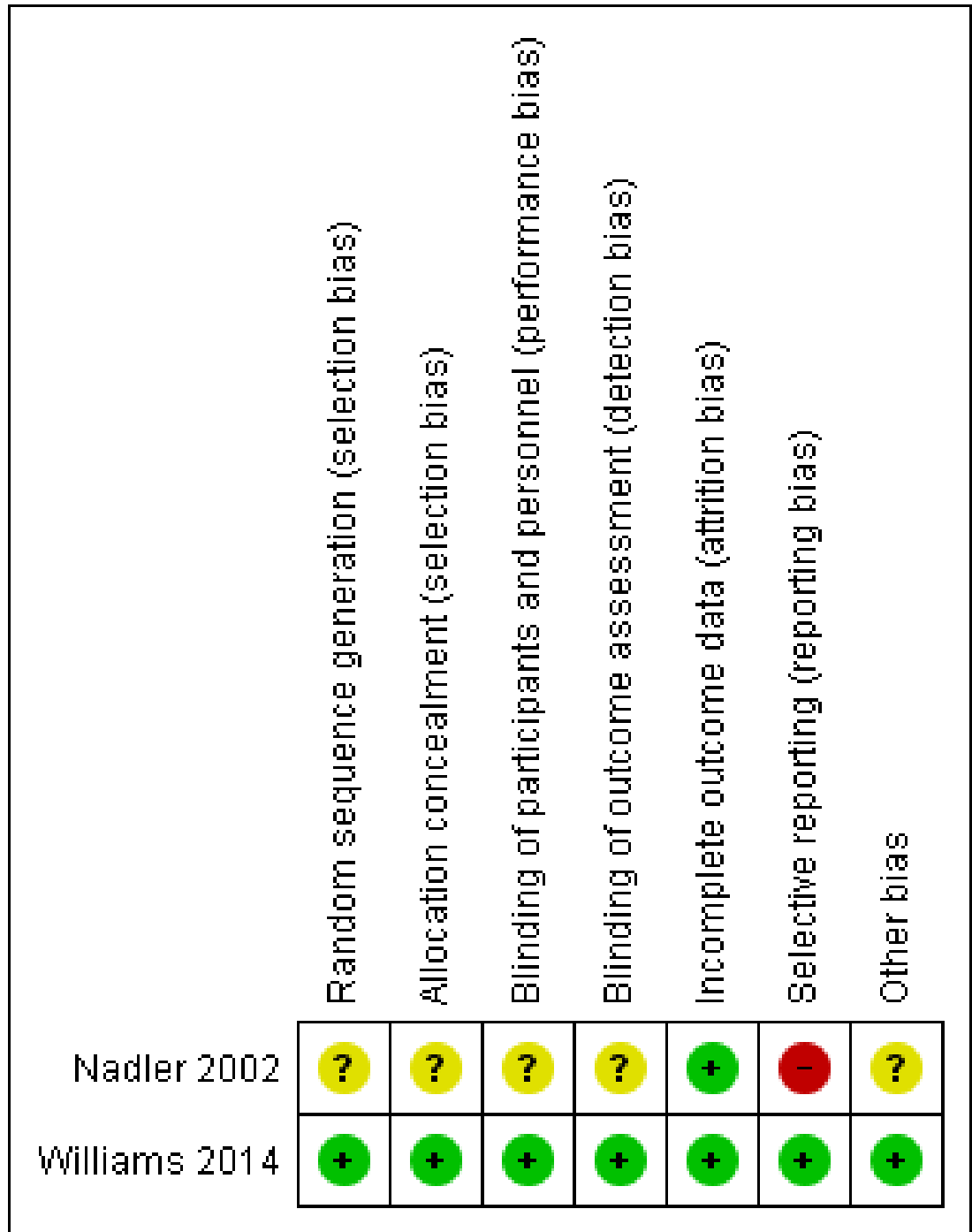

\section{Allocation}

Only one trial had low risk of bias for random sequence generation and allocation concealment (Williams 2014). We judged one trial as unclear for both criteria (Nadler 2002).

\section{Blinding}

One trial had low risk of bias for blinding for participants and personnel and outcome assessor (Williams 2014). We considered one trial unclear for both criteria, as it was not clear which investigator was blinded (personnel or assessor) (Nadler 2002).

\section{Incomplete outcome data}

Both trials successfully described complete outcome data and were rated as low risk of bias for this criterion. The follow-up rate was over $90 \%$ for both trials.

\section{Selective reporting}

Only one trial had low risk of bias for selective reporting (Williams 2014), in which all outcomes of interest were reported. The other trial was rated as high risk of bias for this criterion. Nadler 2002 did not report data for the placebo group for any time point.

\section{Other potential sources of bias}

Both trials received funds from a company that produces paracetamol (Nadler 2002; Williams 2014). One trial was an investigator-initiated trial that received supplementary funding from a pharmaceutical company and reported that the sponsor had no role in conducting the study or analysing the data (Williams 2014). Given this background and the negative trial outcome, this study appears to be free of other sources of bias and was rated as low risk of bias. Nadler 2002 did not report data for the placebo group, and was rated as unclear for other bias.

\section{Effects of interventions}

See: Summary of findings for the main comparison Paracetamol compared with placebo for acute low back pain 


\section{Acute LBP}

\section{Primary outcomes}

One large trial with low risk of bias investigated the effect of paracetamol compared with placebo for acute LBP (Williams 2014). There is high-quality evidence that there is no difference between paracetamol ( $4 \mathrm{~g}$ per day) and placebo for pain at 1 week (immediate term) (mean difference (MD) 1.49, 95\% confidence interval (Cl) -1.30 to 4.28 ), 2 weeks (MD $1.00,95 \% \mathrm{Cl}-1.70$ to 3.70 ), 4 weeks (MD 0.49, $95 \% \mathrm{Cl}-1.99$ to 2.97 ), and 12 weeks (short term) (MD - $0.50,95 \% \mathrm{Cl}-2.92$ to 1.92 ) (Analysis 1.1; Figure 3). There is highquality evidence that there is no difference between paracetamol and placebo for disability at 1 week (immediate term) (MD -0.45, $95 \% \mathrm{Cl}-1.15$ to 0.25 ), 2 weeks (MD $0.00,95 \% \mathrm{Cl}-0.65$ to 0.65 ), 4 weeks (MD $0.05,95 \% \mathrm{Cl}-0.50$ to 0.60 ), and 12 weeks (short term) (MD 0.10, $95 \% \mathrm{Cl}-0.39$ to 0.59 ) (Analysis 1.2; Figure 4).

Figure 3. Forest plot of comparison: 1 Acute low back pain - paracetamol versus placebo, outcome: 1.1 Pain.

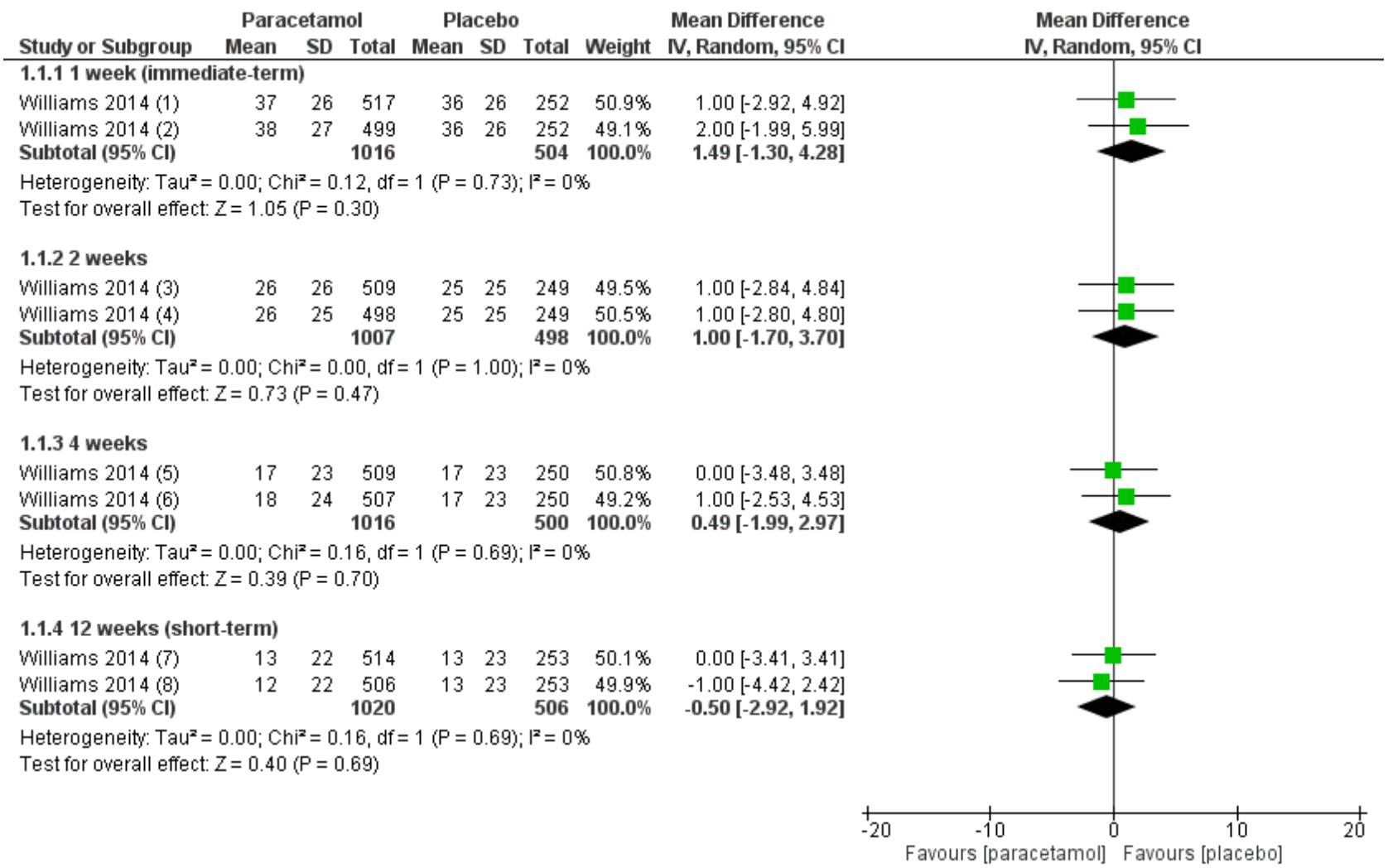

Footnotes

(1) Regular group

(2) As-needed group

(3) Regular group

(4) As-needed group

(5) Regular group

(6) As-needed group

(7) As-needed group

(8) Regular group 
Figure 4. Forest plot of comparison: 1 Acute low back pain - paracetamol versus placebo, outcome: 1.2 Disability

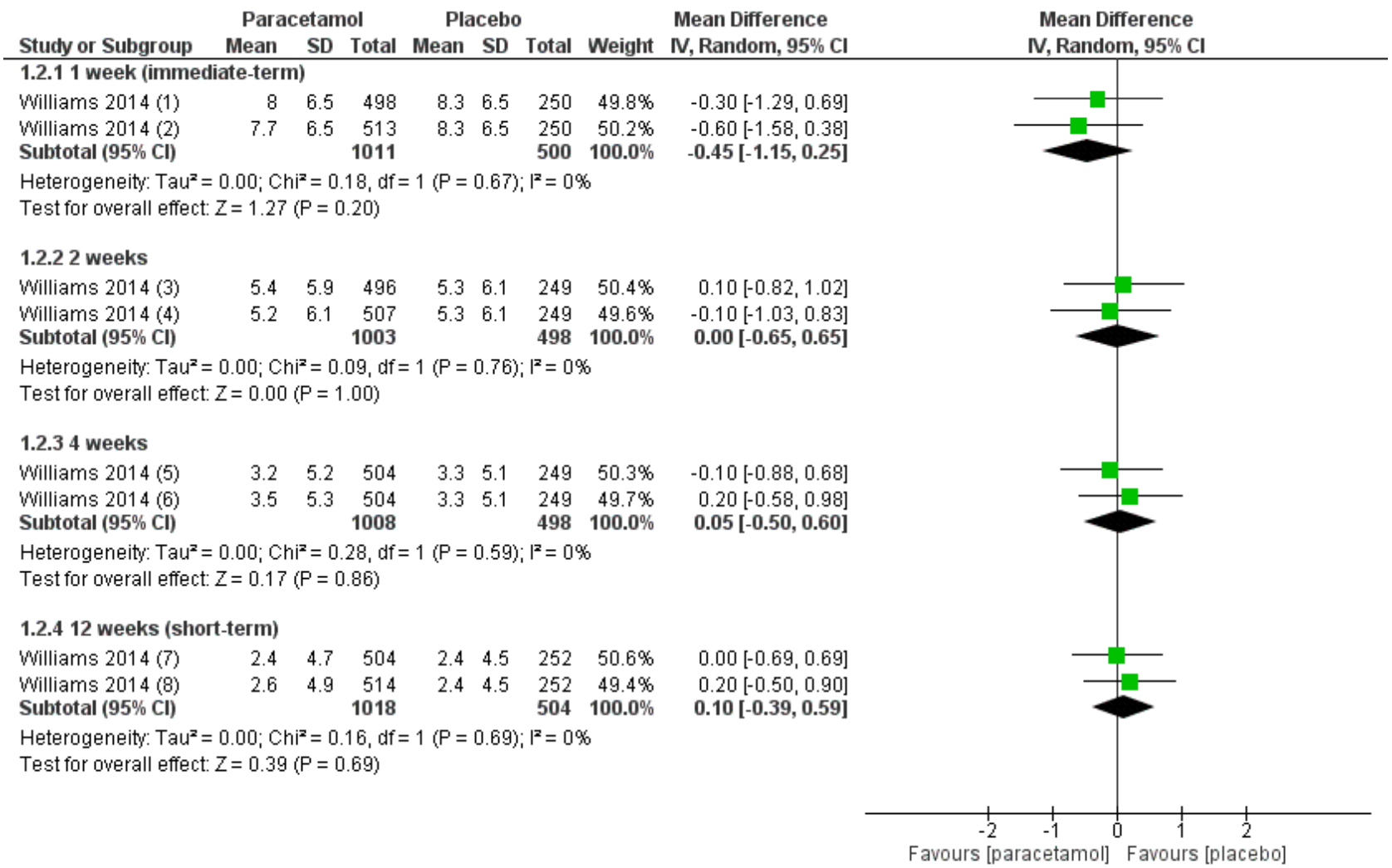

\section{Footnotes}
(1) As-needed group
(2) Regular group
(3) As-needed group
(4) Regular group
(5) Regular group
(6) As-needed group
(7) Regular group
(8) As-needed group

\section{Secondary outcomes}

There is high-quality evidence that paracetamol has no effect on the physical component of quality of life at 4 weeks (MD - $0.79,95 \%$ $\mathrm{Cl}-1.94$ to 0.36 ) and 12 weeks (short term) (MD $0.41,95 \% \mathrm{Cl}-0.91$ to 1.72) (Analysis 1.3), and the mental component of quality life at 4 weeks (MD $-0.60,95 \% \mathrm{Cl}-1.38$ to 0.17 ). We found a statistically significant effect in favour to paracetamol at 12 weeks (short term) for the mental component of quality of life (MD 0.90, $95 \% \mathrm{Cl} 0.08$ to 1.72; $P=0.03$ ), however we did not consider this effect to be clinically important (Analysis 1.4).

There is high-quality evidence that there is no significant difference between paracetamol and placebo for function at 1 week (immediate term) (MD $-0.05,95 \% \mathrm{Cl}-0.32$ to 0.22 ), 2 weeks (MD $-0.15,95 \% \mathrm{Cl}-0.42$ to 0.12 ), 4 weeks (MD $-0.05,95 \% \mathrm{Cl}-0.31$ to 0.21 ), and 12 weeks (short term) (MD $0.00,95 \% \mathrm{Cl}-0.23$ to 0.23 ) (Analysis 1.5). There is also high-quality evidence that there is no significant difference between paracetamol and placebo for global impression of recovery at 1 week (immediate term) (MD $-0.05,95 \% \mathrm{Cl}-0.28$ to 0.18 ), 2 weeks (MD $-0.05,95 \% \mathrm{Cl}-0.28$ to 0.18 ), 4 weeks (MD -0.10 , $95 \% \mathrm{Cl}-0.33$ to 0.13 ), and 12 weeks (short term) (MD $-0.05,95 \% \mathrm{Cl}$ -0.26 to 0.17 ) (Analysis 1.7 ).

Adverse events were reported by 296 (19\%) participants, of which nine participants in the paracetamol group and five in the placebo group reported serious adverse events (that is any event causing hospitalisation or death). However, we observed no differences across groups for total adverse events (risk ratio (RR) $1.07,95 \% \mathrm{Cl}$ 0.86 to 1.33 ) or serious adverse events (RR $0.90,95 \% \mathrm{Cl} 0.30$ to 2.67 ). The reported serious adverse events were unrelated to the study treatment (for example asthma attack, bleeding bowel, infection, hernia, severe back pain, or scheduled surgery) (Analysis 1.6).

We observed no significant differences in the number of participants reporting poor sleep quality at 1 week (immediate term) (RR 1.05, 95\% Cl 0.87 to 1.25 ), 2 weeks (RR $1.01,95 \% \mathrm{Cl} 0.80$ to 1.28 ), 4 weeks (RR $1.11,95 \% \mathrm{Cl} 0.82$ to 1.52 ), and 12 weeks (short term) (RR $1.26,95 \% \mathrm{Cl} 0.90$ to 1.76 ), with high-quality evidence (Analysis 1.8). Finally, there were no significant differences between paracetamol and placebo for patient adherence (RR 1.08, 95\% Cl 0.96 to 1.22 ) (Analysis 1.9) or use of rescue medication (RR 0.50, 95\% $\mathrm{Cl} 0.16$ to 1.55 ) (Analysis 1.10). 


\section{Subacute and chronic LBP}

None of the included trials evaluated patients with subacute or chronic LBP.

\section{DISCUSSION}

\section{Summary of main results}

There is high-quality evidence that there is no difference between paracetamol and placebo for acute LBP on pain, disability, function, quality of life, and sleep quality outcomes at 1 week (immediate term), 2 weeks, 4 weeks, and 12 weeks (short term) follow-ups. There is also no difference on global impression of recovery, patient adherence, and use of rescue medication. Some minor and serious adverse events were reported for either the paracetamol or placebo group, but we found no difference between groups. No trial provided results for long-term follow-up. The results are consistent across all outcome measures and time periods included in this review.

Although we found a statistically significant effect for the mental component of quality life at short term for acute LBP, this result was not clinically important as it was a difference of 0.90 points out of 100 points. This significant effect could also be found by chance due to the large number of analyses in this review.

\section{Overall completeness and applicability of evidence}

None of the trials followed participants for more than 12 weeks (intermediate- or long-term follow-ups); thus the results of this review are restricted to immediate- and short-term follow-ups, that is from 1 week to 12 weeks. Moreover, more than $90 \%$ of the participants analysed in this review are from one large trial (Williams 2014), which included middle-aged Australian participants with acute LBP; thus care should be taken when generalising the findings of this review to other types of patients, such as those with chronic symptoms. In addition, we did not find any trial evaluating paracetamol for subacute or chronic LBP patients.

\section{Quality of the evidence}

The quality of evidence provided in this review was high for the use of paracetamol for acute LBP, which means that further research is very unlikely to change confidence in the estimate of effect. Regarding the risk of bias in the included studies, selective reporting was the only item considered as high risk of bias in one trial (Nadler 2002). However, the trial that accounted for the majority of participants in this review was rated as low risk of bias for all criteria (Williams 2014).

\section{Potential biases in the review process}

Both trials included in this review received funding from a pharmaceutical company (Nadler 2002; Williams 2014). However, in one trial the authors stated that the sponsor had no role in conducting the study or analysing the data, and given the negative outcome of the trial we considered this study to be free of any potential bias regarding conflicts of interest (Williams 2014).
Moreover, we limited our MEDLINE strategy to studies indexed with the MeSH term 'humans' using the limit function in the database. This could potentially exclude eligible studies not indexed with the MeSH term 'human'. We do not think this is an issue in this review as we searched a variety of sources and checked studies from other reviews on the topic.

\section{Agreements and disagreements with other studies or reviews}

The last review on the topic concluded that there was insufficient evidence to assess the efficacy of paracetamol in people with LBP (Davies 2008). The authors of that review could not identify any randomised controlled trial comparing paracetamol to a placebo. Clinical practice guidelines have been recommending paracetamol, especially for acute patients (Koes 2010), based on presumed efficacy for related pain conditions and the safety profile compared to non-steroidal anti-inflammatory drugs (van Tulder 2006). This systematic review provides high-quality evidence that paracetamol is ineffective for acute LBP.

Although we found high-quality evidence for acute LBP, which is unlikely to change with future research, we believe that more studies are needed to resolve the uncertainty about the efficacy of paracetamol for subacute and chronic LBP, before paracetamol is completely removed from the recommendations for the management of LBP.

\section{AUTHORS' CONCLUSIONS}

\section{Implications for practice}

The results argue against the use of paracetamol in the management of acute LBP. It is not possible to make recommendations for or against the use of paracetamol for subacute or chronic LBP as we did not locate any trials.

\section{Implications for research}

The high quality evidence and precise estimate of no effect for acute LBP suggests that no additional trials of paracetamol for acute LBP are required. For acute LBP the research questions include establishing what analgesic medicine(s) should replace paracetamol as the first line analgesic for acute LBP; and evaluating if combination medicines containing paracetamol are effective. In contrast we could not locate any evidence for subacute or chronic LBP and so future research evaluating the efficacy of paracetamol for these patients is required to clarify the uncertainty.

\section{ACKNOWLEDGEMENTS}

Bruno Tirotti Saragiotto is supported by CNPQ (National Council for Scientific and Technological Development), Brazil. Chris Maher is supported by National Health and Medical Research Council of Australia. Gustavo Machado and Marina Pinheiro each hold an International Postgraduate Research Scholarship/Postgraduate Award from the Australian Government. Manuela Ferreira holds a Sydney Medical Foundation Fellowship. 


\section{RE F E R E N C E S}

\section{References to studies included in this review}

\section{Nadler 2002 \{published data only\}}

Nadler SF, Steiner DJ, Erasala GN, Hengehold DA, Hinkle RT, Goodale MB, et al. Continuous low-level heat wrap therapy provides more efficacy than ibuprofen and acetaminophen for acute low back pain. Spine 2002;27:1012-7.

Williams 2014 \{published data only\}

ACTRN12609000966291. Paracetamol for low back pain. https:// www.anzctr.org.au/Trial/Registration/TrialReview.aspx? ACTRN=12609000966291 (accessed 10 August 2015).

* Williams CM, Maher CG, Latimer J, McLachlan AJ, Hancock MJ, Day RO, et al. Efficacy of paracetamol for acute low-back pain: a double-blind, randomised controlled trial. The Lancet 2014;384:1586-96

\section{References to studies excluded from this review}

Borenstein 2001 \{published data only\}

Borenstein D G, Kamin M, Rosenthal N, Karim R, Group Capss Study. Combination tramadol and acetaminophen (Ultracet (TM)) for the treatment of chronic lower back pain. A multicenter, outpatient, randomized, double-blind, placebocontrolled study. Arthritis and Rheumatism 2001;44:S67.

\section{Cabane 1996 \{published data only\}}

Cabane J, Festino C, Lablache Combier B. Comparative trial of lysine acetylsalicylate and paracetamol on pain in daily medical practice. Presse Medicale 1996;25:1367-71.

\section{Childers 2005 \{published data only\}}

Childers MK, Borenstein D, Brown RL, Gershon S, Hale ME, Petri M, et al. Low-dose cyclobenzaprine versus combination therapy with ibuprofen for acute neck or back pain with muscle spasm: a randomized trial. Current Medical Research \& Opinion 2005;21:1485-93.

\section{Codding 2008 \{published data only\}}

Codding C, Levinsky D, Hale M, Thomas J, Lockhart E, Jain R. Analgesic efficacy and safety of controlled-release hydrocodone and acetaminophen tablets, dosed twice daily, for moderate to severe mechanical chronic low-back pain: A randomized, double-blind, placebo-controlled withdrawal trial. Journal of Pain 2008;9:38.

\section{Corts Giner 1989 \{published data only\}}

Corts Giner, JR. DS 103-282: Muscle relaxant in acute lumbalgia or lumbago. (Double blind study of tizanidine + paracetamol vs. placebo + paracetamol). Revista Espanola de Cirugia Osteoarticular 1989;24:119-23.

\section{De Almeida Coimbra 1980 \{published data only\}}

De Almeida Coimbra F, De Araujo Filho NC. A double-blind study comparing the associations chlormezanone-acetaminophen and thiocolchicoside-glafenin in patients with low back pain. Folha Medica 1980;81:113-6.
Derby 2012 \{published data only\}

Derby R, Aprill CN, Lee J, De Palma MJ, Baker RM. Comparison of four different analgesic discogram protocols comparing the incidence of reported pain relief following local anesthetic injection into concordantly painful lumbar intervertebral discs. Pain Medicine 2012;13:1547-53.

Diener 2008 \{published data only\}

Diener HC. Paracetamol is sufficient for acute low back pain. MMW-Fortschritte der Medizin 2008;150:23.

Diener 2008a \{published data only\}

Diener HC. Diclofenac or spinal manipulative therapy are not more effective than standard therapy for acute low back pain. Arzneimitteltherapie 2008;26:222.

Gammaitoni 2003 \{published data only\}

Gammaitoni A R, Galer B S, Lacouture P, Domingos J, Schlagheck T. Effectiveness and safety of new oxycodone/ acetaminophen formulations with reduced acetaminophen for the treatment of low back pain. Pain Medicine 2003;4:21-30.

\section{Garcia Filho 2006 \{published data only\}}

Garcia Filho RJ, Korukian M, dos Santos FPE, Viola DCM, Puertas EB. A randomized, double-blind clinical trial, comparing the combination of caffeine, carisoprodol, sodium diclofenac and paracetamol versus cyclobenzaprine, to evaluate efficacy and safety in the treatment of patients with acute low back pain and lumboischialgia [Ensaio clínico randomizado, duplocego, comparativo entre a associação de cafeína, carisoprodol, diclofenaco sódico e paracetamol e a ciclobenzaprina, para avaliação da eficácia e segurança no tratamento de pacientes com lombalgia e lombociatalgia agudas]. Acta Ortopédica Brasileira 2006;14:11-6.

\section{Gimbel 2001 \{published data only\}}

Gimbel JS, Brugger A, Zhao W, Verburg KM, Geis GS. Efficacy and tolerability of celecoxib versus hydrocodone/acetaminophen in the treatment of pain after ambulatory orthopedic surgery in adults. Clinical Therapeutics 2001;23:228-41.

\section{Hackett 1988 \{published data only\}}

Hackett GI, Seddon D, Kaminski D. Electroacupuncture compared with paracetamol for acute low back pain. Practitioner 1988;232:163-4.

\section{Hingorani 1971 \{published data only\}}

Hingorani K. Orphenadrin-paracetamol in backache - a doubleblind controlled trial. British Journal of Clinical Practice 1971;25:227-31.

\section{Jiang 2008 \{published data only\}}

Jiang N, Guo J, Liu SB, Li DF, Sui JH, Zhou J. Short-term effectiveness observation of oxycodone and acetaminophen tablets for the treatment of lumbar disc heriation [Chinese]. Chinese Journal of New Drugs 2008;17:1798-801. 


\section{Kuntz 1996 \{published data only\}}

Kuntz D, Brossel R. Analgesic effect and clinical tolerability of the combination of paracetamol $500 \mathrm{mg}$ and caffeine $50 \mathrm{mg}$ versus paracetamol $400 \mathrm{mg}$ and dextropropoxyphene $30 \mathrm{mg}$ in back pain. Presse Medicale 1996;25:1171-4.

\section{Larsen 2012 \{published data only\}}

Larsen B, Kuntz S. The diagnosis and pharmacologic management of low back pain. JAAPA: Journal of the American Academy of Physician Assistants (Haymarket Media, Inc.) 2012;25:52-6.

\section{Lee 2008 \{published data only\}}

Lee HKH, Ting SM, Lau FL. A randomised control trial comparing the efficacy of tramadol and paracetamol against ketorolac and paracetamol in the management of musculoskeletal pain in the emergency department. Hong Kong Journal of Emergency Medicine 2008;15:5-11.

\section{Madhusudhan 2013 \{published data only\}}

Madhusudhan SK. Novel analgesic combination of tramadol, paracetamol, caffeine and taurine in the management of moderate to moderately severe acute low back pain. Journal of Orthopaedics 2013;10:144-8.

\section{Martinez-Elizondo 1979 \{published data only\}}

Martinez-Elizondo P. Comparison of the analgesic and antiinflammatory effects of diclofenac, sulindac and naproxen. Multicentric double blind study. Prensa Medica Mexicana 1979;43:38-40.

\section{Matsushita 2012 \{published data only\}}

Matsushita T, Hasebe M, Nishimura A. Phase iii clinical study of tramadol hydrochloride/acetaminophen combination tablet in patients with chronic osteoarthritis pain or chronic low back pain - a randomized withdrawal, double-blind, parallelgroup, placebo-controlled study. Osteoporosis International 2012;23:S85.

\section{McGuinness 1969 \{published data only\}}

McGuinness BW, Lloyd-Jones M, Fowler PD. A double-blind comparative trial of 'parazolidin' and paracetamol. British Journal of Clinical Practice 1969;23:452-5.

Miller 2012 \{published data only\}

Miller SM. Low back pain: pharmacologic management. Primary Care 2012;39:499-510.

\section{Moore 2010 \{published data only\}}

Moore RA, Straube S, Derry S, McQuay HJ. Chronic low back pain analgesic studies - A methodological minefield. Pain 2010;149:431-4.

\section{Muller 1998 \{published data only\}}

Muller FO, Odendaal CL, Muller FR, Raubenheimer J, Middle MV, Kummer M. Comparison of the efficacy and tolerability of a Paracetamol/Codeine fixed-dose combination with tramadol in patients with refractory chronic back pain. ArzneimittelForschung/Drug Research 1998;48:675-9.
Muller 2005 \{published data only\}

Muller R, Giles LG. Long-term follow-up of a randomized clinical trial assessing the efficacy of medication, acupuncture, and spinal manipulation for chronic mechanical spinal pain syndromes. Journal of Manipulative \& Physiological Therapeutics 2005;28:3-11.

\section{NCT00210561 \{published data only\}}

NCT00210561. A study of the effectiveness and safety of tramadol $\mathrm{HCl}$ /acetaminophen compared to placebo in treating acute low back pain. https://clinicaltrials.gov/ct2/show/ NCT00210561 (accessed 10 August 2015).

\section{NCT00643383 \{published data only\}}

NCT00643383. A two-arm study comparing the analgesic efficacy and safety of acetaminophen and tramadol combination BID versus placebo for the treatment of acute low back pain. https://clinicaltrials.gov/ct2/show/NCT00643383 (accessed 10 August 2015).

\section{NCT00736853 \{published data only\}}

NCT00736853. An efficacy and safety study of acetaminophen plus tramadol hydrochloride (JNS013) in participants with chronic pain. https://clinicaltrials.gov/ct2/show/results/ NCT00736853 (accessed 10 August 2015).

\section{NCT01112267 \{published data only\}}

NCT01112267. An efficacy and safety study of extended release (ER) tramadol hydrochloride $(\mathrm{HCl})$ /acetaminophen in participants with chronic low-back pain. https:// clinicaltrials.gov/ct2/show/NCT01112267 (accessed 10 August 2015).

NCT01422291 \{published data only\}

NCT01422291. IV paracetamol, dexketoprofen or morphine for the treatment of low back pain. https://clinicaltrials.gov/ct2/ show/NCT01422291 (accessed 10 August 2015).

\section{NCT01587274 \{published data only\}}

NCT01587274. A randomized study of three medication regimens for acute low back pain. https://clinicaltrials.gov/ct2/ show/NCT01587274 (accessed 10 August 2015).

\section{NCT01776515 \{published data only\}}

NCT01776515. Phase 3 study of tramadol hydrochloride/ acetaminophen SR tab. \& tramadol hydrochloride/ acetaminophen tab. in low back pain patients. https:// clinicaltrials.gov/ct2/show/NCT01776515 (accessed 10 August 2015).

\section{NCT01843660 \{published data only\}}

NCT01843660. An efficacy and safety study of tramadol hydrochloride-paracetamol in treatment of moderate to severe acute neck-shoulder pain and low back pain. https:// clinicaltrials.gov/ct2/show/NCT01843660 (accessed 10 August 2015).

Pallay 2004 \{published data only\}

Pallay RM, Seger W, Adler JL, Ettlinger RE, Quaidoo EA, Lipetz R, et al. Etoricoxib reduced pain and disability and improved quality of life in patients with chronic low back pain: a 3 
month, randomized, controlled trial. Scandinavian Journal of Rheumatology 2004;33:257-66.

\section{Peloso 2004 \{published data only\}}

Peloso PM, Fortin L, Beaulieu A, Kamin M, Rosenthal NR, Protocol TRPCAN Study Group. Analgesic efficacy and safety of tramadol/acetaminophen combination tablets (Ultracet (R)) in treatment of chronic low back pain: A multicenter, outpatient, randomized, double blind, placebo controlled trial. Journal of Rheumatology 2004;31:2454-63.

Ruoff 2003 \{published data only\}

Ruoff G E, Rosenthal N, Jordan D, Karim R, Kamin M, Protocol Capss Study Group. Tramadol/acetaminophen combination tablets for the treatment of chronic lower back pain: a multicenter, randomized, double-blind, placebo-controlled outpatient study. Clinical Therapeutics 2003;25:1123-41.

\section{Schiphorst Preuper 2014 \{published data only\}}

Schiphorst Preuper HR, Geertzen JHB, van Wijhe M, Boonstra AM, Molmans BHW, Dijkstra PU, et al. Do analgesics improve functioning in patients with chronic low back pain? An explorative triple-blinded RCT. European Spine Journal 2014;23:1-7.

\section{Temple 2007 \{published data only\}}

Temple AR, Lynch JM, Vena J, Auiler JF, Gelotte CK. Aminotransferase activities in healthy subjects receiving threeday dosing of 4, 6 , or 8 grams per day of acetaminophen. Clinical Toxicology 2007;45:36-44.

\section{Tervo 1976 \{published data only\}}

Tervo T, Petaja L, Lepisto P. A controlled clinical trial of a muscle relaxant analgesic combination in the treatment of acute lumbago. British Journal of Clinical Practice 1976;30:62-4.

\section{Wetzel 2014 \{published data only\}}

Wetzel L, Zadrazil M, Paternostro-Sluga T, Authried G, KozekLangenecker S, Scharbert G. Intravenous nonopioid analgesic drugs in chronic low back pain patients on chronic opioid treatment. European Journal of Anaesthesiology 2014;31:35-40.

\section{Yarlas 2013 \{published data only\}}

Yarlas A, Miller K, Wen W, Dain B, Lynch SY, Pergolizzi JV, et al. A randomized, placebo-controlled study of the impact of the 7-day buprenorphine transdermal system on health-related quality of life in opioid-naïve patients with moderate-to-severe chronic low back pain. Journal of Pain 2013;14:14-23.

\section{Additional references}

\section{Airaksinen 2006}

Airaksinen O, Brox JI, Cedraschi C, Hildebrandt J, KlaberMoffett J, Kovacs F, et al. Chapter 4. European guidelines for the management of chronic nonspecific low back pain. European Spine Journal 2006;15 Suppl 2:S192-300.

\section{Amar 2007}

Amar PJ, Schiff ER. Acetaminophen safety and hepatotoxicity - where do we go from here?. Expert Opinion on Drug Safety 2007;6:341-55.

\section{Botting 2005}

Botting R, Ayoub SS. COX-3 and the mechanism of action of paracetamol/acetaminophen. Prostaglandins, Leukotrienes and Essential Fatty Acids 2005;72:85-7.

\section{Boutron 2005}

Boutron I, Estellat C, Ravaud P. A review of blinding in randomized controlled trials found results inconsistent and questionable. Journal of Clinical Epidemiology 2005;58:1220-6.

\section{Chan 2006}

Chan AT, Manson JE, Albert CM, Chae CU, Rexrode KM, Curhan GC, et al. Nonsteroidal antiinflammatory drugs, acetaminophen, and the risk of cardiovascular events. Circulation 2006;113:1578-87.

\section{Daly 2008}

Daly FFS, Fountain JS, Murray L, Graudins A, Buckley NA. Guidelines for the management of paracetamol poisoning in Australia and New Zealand--explanation and elaboration. A consensus statement from clinical toxicologists consulting to the Australasian poisons information centres. The Medical Journal of Australia 2008;188:296-301.

\section{Davies 2008}

Davies RA, Maher CG, Hancock MJ. A systematic review of paracetamol for non-specific low back pain. European Spine Journal 2008;17:1423-30.

\section{Egger 1997}

Egger M, Davey Smith G, Schneider M, Minder C. Bias in meta-analysis detected by a simple, graphical test. $B M J$ 1997;315:629-34.

\section{Forman 2005}

Forman JP, Stampfer MJ, Curhan GC. Non-narcotic analgesic dose and risk of incident hypertension in US women. Hypertension 2005;46:500-7.

\section{Furlan 2015}

Furlan AD, Malmivaara A, Chou R, Maher CG, Deyo RA, Schoene M, et al. 2015 updated method guideline for systematic reviews in the Cochrane Back and Neck Group. Spine (Phila Pa 1976) 2015 Jul 22 [Epub ahead of print].

\section{Global Burden of Disease Study 2015}

Global Burden of Disease Study Collaborators. Global, regional, and national incidence, prevalence, and years lived with disability for 301 acute and chronic diseases and injuries in 188 countries, 1990-2013: a systematic analysis for the Global Burden of Disease Study 2013. The Lancet 2015 Jun 7 [Epub ahead of print].

\section{Graham 2013}

Graham GG, Davies MJ, Day RO, Mohamudally A, Scott KF. The modern pharmacology of paracetamol: therapeutic actions, mechanism of action, metabolism, toxicity and recent pharmacological findings. Inflammopharmacology 2013;21:201-32. 


\section{Guyatt 2011}

Guyatt GH, Oxman AD, Kunz R, Brozek J, Alonso-Coello P, Rind D, et al. GRADE guidelines 6 . Rating the quality of evidence - imprecision. Journal of Clinical Epidemiology 2011;64:1283-93.

\section{Guyatt 2011a}

Guyatt GH, Oxman AD, Kunz R, Woodcock J, Brozek J, Helfand M, et al. GRADE guidelines: 8 . Rating the quality of evidence - indirectness. Journal of Clinical Epidemiology 2011;64:1303-10.

\section{Guyatt 2011b}

Guyatt GH, Oxman AD, Montori V, Vist G, Kunz R, Brozek J, et al. GRADE guidelines: 5 . Rating the quality of evidence - publication bias. Journal of Clinical Epidemiology 2011;64:1277-82.

\section{Henschke 2008}

Henschke N, Maher CG, Refshauge KM, Herbert RD, Cumming RG, Bleasel J, et al. Prognosis in patients with recent onset low back pain in Australian primary care: inception cohort study. BMJ 2008;337:a171.

\section{Higgins 2011}

Higgins JPT, Green S (editors). Cochrane Handbook for Systematic Reviews of Interventions. Version 5.1.0 (updated March 2011). The Cochrane Collaboration, 2011. Available from www.cochrane-handbook.org

\section{Hinz 2008}

Hinz B, Cheremina O, Brune K. Acetaminophen (paracetamol) is a selective cyclooxygenase- 2 inhibitor in man. The FASEB Journal 2008;22:383-90.

\section{Hinz 2012}

Hinz B, Brune K. Paracetamol and cyclooxygenase inhibition: is there a cause for concern?. Annals of the Rheumatic Diseases 2012;71:20-5.

\section{Jozwiak-Bebenista 2014}

Jozwiak-Bebenista M, Nowak JZ. Paracetamol: mechanism of action, applications and safety concern. Acta Poloniae Pharmaceutica 2014;71:11-23.

\section{Koes 2010}

Koes BW, van Tulder M, Lin CW, Macedo LG, McAuley J, Maher C. An updated overview of clinical guidelines for the management of non-specific low back pain in primary care. European Spine Journal 2010;19:2075-94.

\section{Menezes 2009}

Menezes Costa LC, Maher CG, McAuley JH, Hancock MJ, Herbert RD, Refshauge KM, et al. Prognosis for patients with chronic low back pain: inception cohort study. BMJ 2009;339:b3829.

\section{Menezes 2012}

Menezes Costa LC, Maher CG, Hancock MJ, McAuley JH, Herbert RD, Costa LO. The prognosis of acute and persistent low-back pain: a meta-analysis. Canadian Medical Association Journal 2012;184:E613-24.

\section{Mueller 2007}

Mueller PS, Montori VM, Bassler D, Koenig BA, Guyatt GH. Ethical issues in stopping randomized trials early because of apparent benefit. Ideas and Opinions 2007;146:878-82.

\section{Ostelo 2008}

Ostelo RW, Deyo RA, Stratford P, Waddell G, Croft P, Von Korff M, et al. Interpreting change scores for pain and functional status in low back pain: towards international consensus regarding minimal important change. Spine 2008;33:90-4.

\section{Pengel 2003}

Pengel LH, Herbert RD, Maher CG, Refshauge KM. Acute low back pain: systematic review of its prognosis. $B M J$ 2003;327:323.

\section{Roberts 2015}

Roberts E, Delgado Nunes V, Buckner S, Latchem S, Constanti M, Miller P, et al. Paracetamol: not as safe as we thought? A systematic literature review of observational studies. Annals of Rheumatic Diseases 2015 Mar 2 [Epub ahead of print].

\section{Sheen 2002}

Sheen CL, Dillon JF, Bateman DN, Simpson KJ, Macdonald TM. Paracetamol toxicity: epidemiology, prevention and costs to the health-care system. QJM 2002;95:609-19.

\section{van Tulder 2003}

van Tulder M, Furlan A, Bombardier C, Bouter L, Editorial Board of the Cochrane Collaboration Back Review Group. Updated method guidelines for systematic reviews in the Cochrane Collaboration Back Review Group. Spine 2003;28(12):1290-9.

\section{van Tulder 2006}

van Tulder M, Becker A, Bekkering T, Breen A, del Real MT, Hutchinson $A$, et al. Chapter 3. European guidelines for the management of acute nonspecific low back pain in primary care. European Spine Journal 2006;15 Suppl 2:S169-91.

\section{Wandel 2010}

Wandel S, Jüni P, Tendal B, Nüesch E, Villiger PM, Welton NJ, et al. Effects of glucosamine, chondroitin, or placebo in patients with osteoarthritis of hip or knee: network meta-analysis. BMJ 2010;16:c4675.

\section{References to other published versions of this review Machado 2015}

Machado GC, Maher CG, Ferreira PH, Pinheiro MB, Lin CWC, Day RO, et al. Efficacy and safety of paracetamol for spinal pain and osteoarthritis: systematic review and meta-analysis of randomised placebo controlled trials. BMJ 2015;350:h1225.

* Indicates the major publication for the study 
CHARACTERISTICS OF STUDIES

Characteristics of included studies [ordered by study ID]

Nadler 2002

\begin{tabular}{|c|c|}
\hline Methods & Randomised, actively controlled, multicentre, single-blind study \\
\hline \multirow[t]{3}{*}{ Participants } & $\begin{array}{l}\text { Population source: } 371 \text { participants with acute non-specific LBP of at least moderate pain intensity } \\
\text { (133 participants randomised to paracetamol or placebo group). The study was conducted at } 11 \text { sites. }\end{array}$ \\
\hline & $\begin{array}{l}\text { Inclusion criteria: Pain of moderate intensity ( } 2 \text { or more on a 6-point scale), age } 18 \text { to } 55 \text { years (inclu- } \\
\text { sive), ambulatory status, no low back trauma within the preceding } 48 \text { hours, and an answer of "yes" to } \\
\text { the question "Do the muscles in your low back hurt?" }\end{array}$ \\
\hline & $\begin{array}{l}\text { Exclusion criteria: Any evidence or history of radiculopathy or other neurologic deficits (e.g. abnor- } \\
\text { mal straight-leg-raise test results, patellar reflexes, or bowel or bladder function), or a history of back } \\
\text { surgery, fibromyalgia, diabetes mellitus, peripheral vascular disease, osteoporosis, gastrointestinal ul- } \\
\text { cers, gastrointestinal bleeding or perforation, renal disease, pulmonary oedema, cardiomyopathy, liver } \\
\text { disease, intrinsic coagulation defects, bleeding diseases or anticoagulant therapy (e.g. warfarin), daily } \\
\text { back pain for more than } 3 \text { consecutive months, or hypersensitivity to acetaminophen, non-steroidal an- } \\
\text { ti-inflammatory drugs, or heat }\end{array}$ \\
\hline
\end{tabular}

1. heat wrap (ThermaCare Heat Wrap; Procter \& Gamble, Cincinnati, $\mathrm{OH}$ ), which wraps around the lumbar region of the torso and uses a velcro-like closure, heats to 104 degrees $F$ ( 40 degrees $C$ ) within 30 minutes of exposure to air, and maintains this temperature continuously for 8 hours of wear;

2. oral ibuprofen, 2 tablets 3 times daily for a total dose of $1200 \mathrm{mg}$, with oral placebo 1 time daily for blinding from the acetaminophen group;

3. oral acetaminophen, 2 tablets 4 times daily for a total of $4000 \mathrm{mg}$ dose total;

4. oral placebo, 2 tablets 4 times daily; and

5. unheated back wrap.

All treatments were administered on 2 consecutive days

Outcomes $\quad$ Primary: pain relief (NRS 0 to 5), disability (Roland Morris 0 to 24).

Secondary: safety.

Notes Funding: This study was funded by the Procter \& Gamble Company.

Conflicts of interest: Industry funds were received to support this work. 6 out of 8 study authors are employees of the Procter \& Gamble Health Sciences Institute, and 1 author is a paid consultant for Procter \& Gamble Company.

There is no information on the dates when the study was conducted

\section{Risk of bias}

\begin{tabular}{lll}
\hline Bias & Authors' judgement & Support for judgement \\
\hline $\begin{array}{l}\text { Random sequence genera- } \\
\text { tion (selection bias) }\end{array}$ & Unclear risk & Quote: "subjects were randomized to treatment by a ratio of 6:6:6:1:1". \\
& & Comment: Unclear \\
\hline $\begin{array}{l}\text { Allocation concealment } \\
\text { (selection bias) }\end{array}$ & Unclear risk & Comment: Unclear \\
\hline
\end{tabular}


Nadler 2002 (Continued)
Blinding of participants
Unclear risk
Quote: "single (investigator) blind". and personnel (perfor-
Comment: Unclear if blinding was done for the assessor or the care provider
mance bias)

All outcomes

\begin{tabular}{|c|c|c|}
\hline $\begin{array}{l}\text { Blinding of outcome as- } \\
\text { sessment (detection bias) } \\
\text { All outcomes }\end{array}$ & Unclear risk & $\begin{array}{l}\text { Quote: "single (investigator) blind". } \\
\text { Comment: Unclear if the assessor or the care provider was blinded }\end{array}$ \\
\hline
\end{tabular}

\begin{tabular}{|c|c|c|}
\hline $\begin{array}{l}\text { Incomplete outcome data } \\
\text { (attrition bias) } \\
\text { All outcomes }\end{array}$ & Low risk & $\begin{array}{l}9 / 113 \text { not evaluable for primary efficacy variable in the intervention group; } \\
1 / 20 \text { not evaluable for primary efficacy variable in the control group }\end{array}$ \\
\hline $\begin{array}{l}\text { Selective reporting (re- } \\
\text { porting bias) }\end{array}$ & High risk & $\begin{array}{l}\text { Comment: The placebo group is listed in the methods, but no data for this } \\
\text { group are reported for any time point }\end{array}$ \\
\hline Other bias & Unclear risk & $\begin{array}{l}\text { Comment: Data for the placebo group are unavailable. This study received } \\
\text { funds from a company that produces paracetamol }\end{array}$ \\
\hline
\end{tabular}

Williams 2014

\begin{tabular}{ll}
\hline Methods & Multicentre, double-dummy, randomised, placebo-controlled trial \\
\hline Participants & $\begin{array}{l}\text { Population source: } 1653 \text { participants (acetaminophen } \mathrm{n}=550, \text { acetaminophen as required } \mathrm{n}=546, \\
\text { placebo } \mathrm{n}=547 \text { ) recruited from primary care clinicians (general practitioners, pharmacists, or physio- } \\
\text { therapists) across Sydney, Australia, screened consecutive people who sought care for LBP directly or } \\
\text { in response to a community advertisement. }\end{array}$
\end{tabular}

Inclusion criteria: A new episode of acute LBP (defined as pain between the 12th rib and buttock crease that was less than 6 weeks' duration and preceded by 1 month of no pain) with or without leg pain, and at least moderate-intensity pain (measured by an adaptation of item 7 of the SF-36).

Exclusion criteria: Suspected serious spinal pathology; currently using full regular recommended doses of an analgesic; spinal surgery in the preceding 6 months; contraindication to paracetamol; using psychotropic medication for a health condition deemed to prevent reliable recording of study information; or pregnant or planning pregnancy

Interventions

Participants were asked to take 2 types of tablets for up to 4 weeks: 2 tablets from the regular box every 6 to 8 hours ( 6 tablets per day), and 1 or 2 tablets from the as-needed box when needed for pain relief ( 4 to 6 hours apart, to a maximum of 8 tablets per day). Participants in the regular group received 665 mg modified-release paracetamol tablets in the regular box and placebo tablets in the as-needed box. Participants in the as-needed group received placebo tablets in the regular box and $500 \mathrm{mg}$ paracetamol immediate-release tablets in the as-needed box. Participants in the placebo group received placebo tablets in both boxes
Outcomes
Pain (0 to 10), disability (Roland Morris 0 to 24), function (Patient-Specific Functional Scale), quality of life (SF-12), global impression of recovery (Global Perceived Effect scale), sleep quality, adherence, ad- verse events

Conflicts of interest: One author received funding for a research scholarship from GlaxoSmithKline, and another author received funding to review teaching materials prepared by GlaxoSmithKline. The other authors declared no competing interests.

There is no information on the dates when the study was conducted 
Williams 2014 (Continued)

\section{Risk of bias}

\begin{tabular}{|c|c|c|}
\hline Bias & Authors' judgement & Support for judgement \\
\hline $\begin{array}{l}\text { Random sequence genera- } \\
\text { tion (selection bias) }\end{array}$ & Low risk & $\begin{array}{l}\text { Quote: "computer-generated randomisation schedule". } \\
\text { Comment: Adequate }\end{array}$ \\
\hline $\begin{array}{l}\text { Allocation concealment } \\
\text { (selection bias) }\end{array}$ & Low risk & $\begin{array}{l}\text { Quote: "concealed random allocation"; "Research staff not involved in prepa- } \\
\text { ration of medicine boxes collected baseline information by telephone and in- } \\
\text { structed patients to open the box and begin treatment". } \\
\text { Comment: Adequate }\end{array}$ \\
\hline $\begin{array}{l}\text { Blinding of participants } \\
\text { and personnel (perfor- } \\
\text { mance bias) } \\
\text { All outcomes }\end{array}$ & Low risk & $\begin{array}{l}\text { Quote: "Clinicians, participants, and staff collecting outcome data, assessing } \\
\text { outcomes, and analysing data were masked to group allocation". } \\
\text { Comment: Adequate }\end{array}$ \\
\hline $\begin{array}{l}\text { Blinding of outcome as- } \\
\text { sessment (detection bias) } \\
\text { All outcomes }\end{array}$ & Low risk & $\begin{array}{l}\text { Quote: "Clinicians, participants, and staff collecting outcome data, assessing } \\
\text { outcomes, and analysing data were masked to group allocation". } \\
\text { Comment: Adequate }\end{array}$ \\
\hline $\begin{array}{l}\text { Incomplete outcome data } \\
\text { (attrition bias) } \\
\text { All outcomes }\end{array}$ & Low risk & $\begin{array}{l}31 / 1099 \text { withdrawn from intervention groups; } 15 / 553 \text { withdrawn from control } \\
\text { group. The completeness of survival data, measured by the completeness in- } \\
\text { dex, was } 94.4 \%\end{array}$ \\
\hline $\begin{array}{l}\text { Selective reporting (re- } \\
\text { porting bias) }\end{array}$ & Low risk & All outcomes that are of interest in the review have been reported \\
\hline Other bias & Low risk & $\begin{array}{l}\text { This study was an investigator-initiated trial that received supplementary } \\
\text { funding from a pharmaceutical company and reported that the sponsor had } \\
\text { no role in conducting the study or analysing the data. Given this background } \\
\text { and the negative trial outcome, this study appears to be free of other sources } \\
\text { of bias and met this criterion }\end{array}$ \\
\hline
\end{tabular}

LBP: low back pain

NRS: Numeric Rating Scale

SF-12: 12-Item Short Form Health Survey

SF-36: 36-Item Short Form Health Survey

Characteristics of excluded studies [ordered by study ID]

\begin{tabular}{ll}
\hline Study & Reason for exclusion \\
\hline Borenstein 2001 & Combination of medications \\
\hline Cabane 1996 & No placebo group \\
\hline Childers 2005 & No placebo group \\
\hline Codding 2008 & Combination of medications \\
\hline Corts Giner 1989 & No placebo group \\
\hline
\end{tabular}




\begin{tabular}{|c|c|}
\hline Study & Reason for exclusion \\
\hline De Almeida Coimbra 1980 & Not RCT \\
\hline Derby 2012 & Not RCT \\
\hline Diener 2008 & Commentary \\
\hline Diener 2008a & Commentary \\
\hline Gammaitoni 2003 & Not RCT \\
\hline Garcia Filho 2006 & Combination of medications \\
\hline Gimbel 2001 & Combination of medications \\
\hline Hackett 1988 & No placebo group \\
\hline Hingorani 1971 & No placebo group \\
\hline Jiang 2008 & No placebo group \\
\hline Kuntz 1996 & No placebo group \\
\hline Larsen 2012 & Not RCT \\
\hline Lee 2008 & No placebo group \\
\hline Madhusudhan 2013 & No placebo group \\
\hline Martinez-Elizondo 1979 & No paracetamol group \\
\hline Matsushita 2012 & No paracetamol group \\
\hline McGuinness 1969 & No placebo group \\
\hline Miller 2012 & Not RCT \\
\hline Moore 2010 & Not RCT \\
\hline Muller 1998 & Combination of medications \\
\hline Muller 2005 & No placebo group \\
\hline NCT00210561 & Combination of paracetamol and other medications \\
\hline NCT00643383 & Combination of paracetamol and other medications \\
\hline NCT00736853 & Combination of paracetamol and other medications \\
\hline NCT01112267 & Combination of paracetamol and other medications \\
\hline NCT01422291 & No placebo group \\
\hline NCT01587274 & Combination of paracetamol and other medications \\
\hline NCT01776515 & Combination of paracetamol and other medications \\
\hline
\end{tabular}




\begin{tabular}{ll}
\hline Study & Reason for exclusion \\
\hline NCT01843660 & Combination of paracetamol and other medications \\
\hline Pallay 2004 & No paracetamol group \\
\hline Peloso 2004 & Combination of medications \\
\hline Ruoff 2003 & Combination of medications \\
\hline Schiphorst Preuper 2014 & Combination of medications \\
\hline Temple 2007 & Not low back pain \\
\hline Tervo 1976 & No placebo group \\
\hline Wetzel 2014 & Retracted study \\
\hline Yarlas 2013 & No paracetamol group \\
\hline
\end{tabular}

$\mathrm{RCT}$ : randomised controlled trial

DATA AND ANALYSES

\section{Comparison 1. Acute low back pain - paracetamol versus placebo}

\begin{tabular}{|c|c|c|c|c|}
\hline $\begin{array}{l}\text { Outcome or subgroup } \\
\text { title }\end{array}$ & No. of studies & $\begin{array}{l}\text { No. of partici- } \\
\text { pants }\end{array}$ & Statistical method & Effect size \\
\hline 1 Pain & 1 & & Mean Difference (IV, Random, 95\% CI) & Subtotals only \\
\hline $\begin{array}{l}1.11 \text { week (immedi- } \\
\text { ate-term) }\end{array}$ & 1 & 1520 & Mean Difference (IV, Random, 95\% CI) & $1.49[-1.30,4.28]$ \\
\hline 1.22 weeks & 1 & 1505 & Mean Difference (IV, Random, 95\% CI) & $1.0[-1.70,3.70]$ \\
\hline 1.34 weeks & 1 & 1516 & Mean Difference (IV, Random, 95\% CI) & $0.49[-1.99,2.97]$ \\
\hline 1.412 weeks (short-term) & 1 & 1526 & Mean Difference (IV, Random, 95\% CI) & $-0.50[-2.92,1.92]$ \\
\hline 2 Disability & 1 & & Mean Difference (IV, Random, 95\% CI) & Subtotals only \\
\hline $\begin{array}{l}2.11 \text { week (immedi- } \\
\text { ate-term) }\end{array}$ & 1 & 1511 & Mean Difference (IV, Random, 95\% CI) & $-0.45[-1.15,0.25]$ \\
\hline 2.22 weeks & 1 & 1501 & Mean Difference (IV, Random, 95\% CI) & $0.00[-0.65,0.65]$ \\
\hline 2.34 weeks & 1 & 1506 & Mean Difference (IV, Random, 95\% CI) & $0.05[-0.50,0.60]$ \\
\hline 2.412 weeks (short-term) & 1 & 1522 & Mean Difference (IV, Random, 95\% CI) & $0.10[-0.39,0.59]$ \\
\hline $\begin{array}{l}3 \text { Quality of life, physical } \\
\text { component }\end{array}$ & 1 & & Mean Difference (IV, Random, 95\% CI) & Subtotals only \\
\hline
\end{tabular}




\begin{tabular}{|c|c|c|c|c|}
\hline $\begin{array}{l}\text { Outcome or subgroup } \\
\text { title }\end{array}$ & No. of studies & $\begin{array}{l}\text { No. of partici- } \\
\text { pants }\end{array}$ & Statistical method & Effect size \\
\hline 3.14 weeks & 1 & 1145 & Mean Difference (IV, Random, 95\% Cl) & $-0.79[-1.94,0.36]$ \\
\hline 3.212 weeks (short-term) & 1 & 760 & Mean Difference (IV, Random, 95\% CI) & $0.41[-0.91,1.72]$ \\
\hline $\begin{array}{l}4 \text { Quality of life, mental } \\
\text { component }\end{array}$ & 1 & & Mean Difference (IV, Random, 95\% CI) & Subtotals only \\
\hline 4.14 weeks & 1 & 1145 & Mean Difference (IV, Random, 95\% Cl) & $-0.60[-1.38,0.17]$ \\
\hline 4.212 weeks (short-term) & 1 & 760 & Mean Difference (IV, Random, 95\% Cl) & $0.90[0.08,1.72]$ \\
\hline 5 Function & 1 & & Mean Difference (IV, Random, 95\% Cl) & Subtotals only \\
\hline $\begin{array}{l}5.11 \text { week (immedi- } \\
\text { ate-term) }\end{array}$ & 1 & 1511 & Mean Difference (IV, Random, 95\% Cl) & $-0.05[-0.32,0.22]$ \\
\hline 5.22 weeks & 1 & 1499 & Mean Difference (IV, Random, 95\% Cl) & $-0.15[-0.42,0.12]$ \\
\hline 5.34 weeks & 1 & 1502 & Mean Difference (IV, Random, 95\% Cl) & $-0.05[-0.31,0.21]$ \\
\hline 5.412 weeks (short-term) & 1 & 1518 & Mean Difference (IV, Random, 95\% CI) & $0.0[-0.23,0.23]$ \\
\hline 6 Adverse events & 1 & & Risk Ratio (M-H, Random, 95\% Cl) & Subtotals only \\
\hline $\begin{array}{l}6.1 \text { Any adverse events } \\
\text { (up to } 12 \text { weeks) }\end{array}$ & 1 & 1624 & Risk Ratio (M-H, Random, 95\% Cl) & $1.07[0.86,1.33]$ \\
\hline $\begin{array}{l}\text { 6.2 Serious adverse } \\
\text { events (up to } 12 \text { weeks) }\end{array}$ & 1 & 1643 & Risk Ratio (M-H, Random, 95\% Cl) & $0.90[0.30,2.67]$ \\
\hline $\begin{array}{l}7 \text { Global impression of } \\
\text { recovery }\end{array}$ & 1 & & Mean Difference (IV, Random, 95\% CI) & Subtotals only \\
\hline $\begin{array}{l}7.11 \text { week (immedi- } \\
\text { ate-term) }\end{array}$ & 1 & 1515 & Mean Difference (IV, Random, 95\% CI) & $-0.05[-0.28,0.18]$ \\
\hline 7.22 weeks & 1 & 1501 & Mean Difference (IV, Random, 95\% CI) & $-0.05[-0.28,0.18]$ \\
\hline 7.34 weeks & 1 & 1511 & Mean Difference (IV, Random, 95\% CI) & $-0.10[-0.33,0.13]$ \\
\hline 7.412 weeks (short-term) & 1 & 1523 & Mean Difference (IV, Random, 95\% Cl) & $-0.05[-0.26,0.17]$ \\
\hline 8 Poor sleep quality & 1 & & Risk Ratio (M-H, Random, 95\% Cl) & Subtotals only \\
\hline $\begin{array}{l}8.11 \text { week (immedi- } \\
\text { ate-term) }\end{array}$ & 1 & 1511 & Risk Ratio (M-H, Random, 95\% Cl) & $1.05[0.87,1.25]$ \\
\hline 8.22 weeks & 1 & 1500 & Risk Ratio (M-H, Random, 95\% Cl) & $1.01[0.80,1.28]$ \\
\hline 8.34 weeks & 1 & 1510 & Risk Ratio (M-H, Random, 95\% Cl) & $1.11[0.82,1.52]$ \\
\hline 8.412 weeks (short-term) & 1 & 1523 & Risk Ratio (M-H, Random, 95\% Cl) & $1.26[0.90,1.76]$ \\
\hline 9 Patient adherence & 1 & & Risk Ratio (M-H, Random, 95\% Cl) & Subtotals only \\
\hline
\end{tabular}




\begin{tabular}{lllll}
\hline $\begin{array}{l}\text { Outcome or subgroup } \\
\text { title }\end{array}$ & No. of studies & $\begin{array}{l}\text { No. of partici- } \\
\text { pants }\end{array}$ & Statistical method & Effect size \\
\hline 9.14 weeks & 1 & 1311 & Risk Ratio (M-H, Random, 95\% Cl) & $1.08[0.96,1.22]$ \\
\hline $\begin{array}{l}10 \text { Use of rescue medica- } \\
\text { tion }\end{array}$ & 1 & Risk Ratio (M-H, Random, 95\% Cl) & Subtotals only \\
\hline 10.1 Up to 2 weeks & 1 & 1548 & Risk Ratio (M-H, Random, 95\% Cl) & $0.50[0.16,1.55]$ \\
\hline
\end{tabular}

Analysis 1.1. Comparison 1 Acute low back pain - paracetamol versus placebo, Outcome 1 Pain.

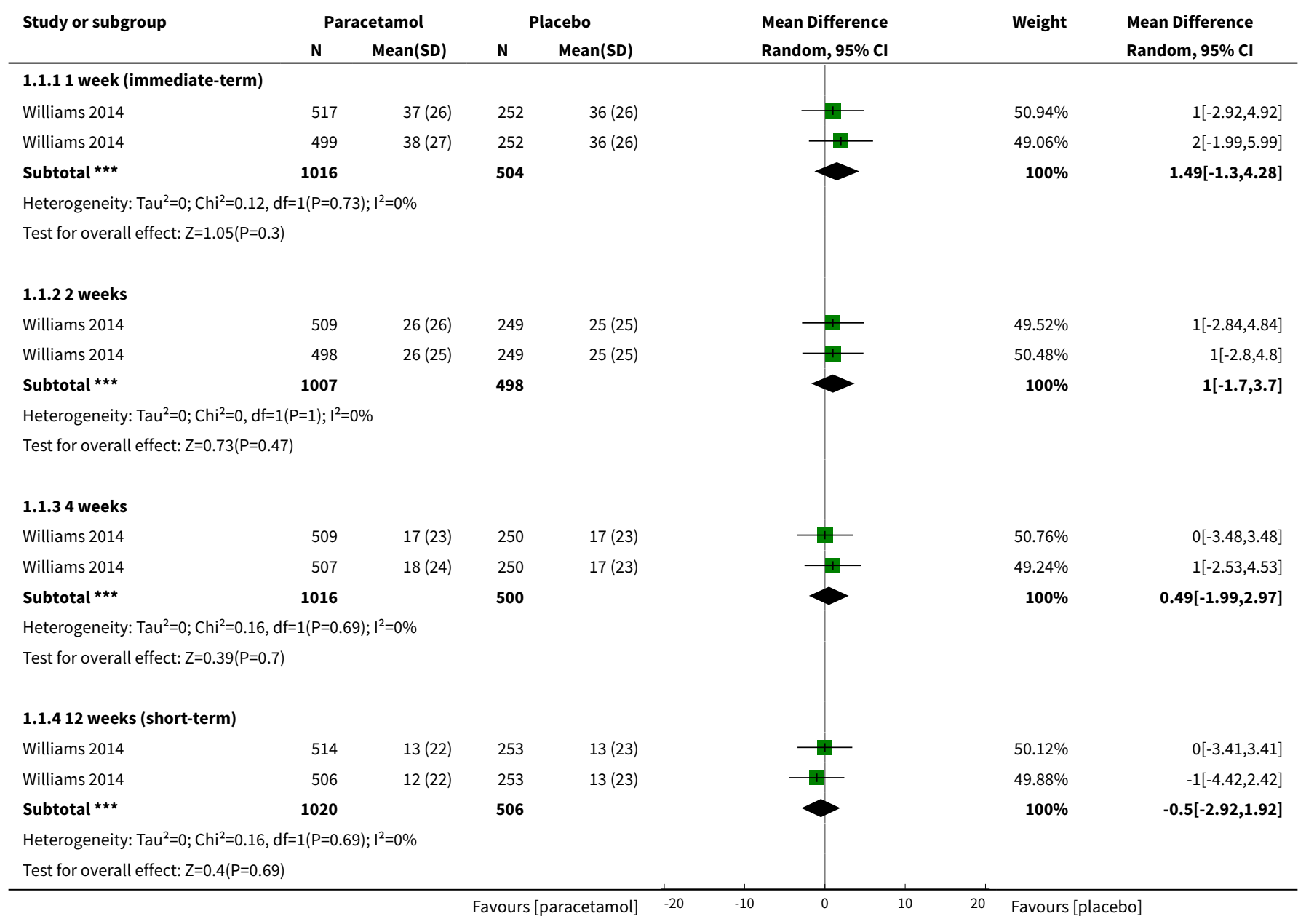

Analysis 1.2. Comparison 1 Acute low back pain - paracetamol versus placebo, Outcome 2 Disability.

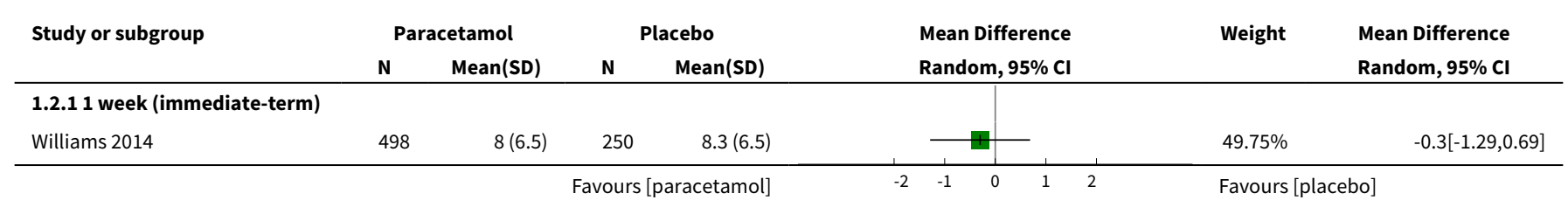




\begin{tabular}{|c|c|c|c|c|c|c|c|}
\hline \multirow{3}{*}{$\begin{array}{l}\text { Study or subgroup } \\
\text { Williams } 2014\end{array}$} & \multicolumn{2}{|c|}{ Paracetamol } & \multicolumn{2}{|c|}{ Placebo } & \multirow{2}{*}{$\begin{array}{l}\text { Mean Difference } \\
\text { Random, } 95 \% \mathrm{CI}\end{array}$} & \multirow[t]{2}{*}{ Weight } & \multirow{2}{*}{$\begin{array}{l}\text { Mean Difference } \\
\text { Random, } 95 \% \mathrm{Cl}\end{array}$} \\
\hline & $\mathbf{N}$ & Mean(SD) & $\mathbf{N}$ & Mean(SD) & & & \\
\hline & 513 & $7.7(6.5)$ & 250 & $8.3(6.5)$ & 1 & $50.25 \%$ & $-0.6[-1.58,0.38]$ \\
\hline 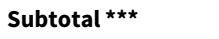 & 1011 & & 500 & & & $100 \%$ & $-0.45[-1.15,0.25]$ \\
\hline \multicolumn{8}{|c|}{ Heterogeneity: $\operatorname{Tau}^{2}=0 ; \mathrm{Chi}^{2}=0.18, \mathrm{df}=1(\mathrm{P}=0.67) ; \mathrm{I}^{2}=0 \%$} \\
\hline \multicolumn{8}{|c|}{ Test for overall effect: $Z=1.27(P=0.2)$} \\
\hline \multicolumn{8}{|l|}{ 1.2.2 2 weeks } \\
\hline Williams 2014 & 496 & $5.4(5.9)$ & 249 & $5.3(6.1)$ & & $50.36 \%$ & $0.1[-0.82,1.02]$ \\
\hline Williams 2014 & 507 & $5.2(6.1)$ & 249 & $5.3(6.1)$ & & $49.64 \%$ & $-0.1[-1.03,0.83]$ \\
\hline Subtotal $* \star \star$ & 1003 & & 498 & & & $100 \%$ & $0[-0.65,0.65]$ \\
\hline \multicolumn{8}{|c|}{ Heterogeneity: $\operatorname{Tau}^{2}=0 ; \mathrm{Chi}^{2}=0.09, \mathrm{df}=1(\mathrm{P}=0.76) ; \mathrm{I}^{2}=0 \%$} \\
\hline \multicolumn{8}{|c|}{ Test for overall effect: $Z=0(P=1)$} \\
\hline \multicolumn{8}{|l|}{ 1.2.3 4 weeks } \\
\hline Williams 2014 & 504 & $3.2(5.2)$ & 249 & $3.3(5.1)$ & & $50.33 \%$ & $-0.1[-0.88,0.68]$ \\
\hline Williams 2014 & 504 & $3.5(5.3)$ & 249 & $3.3(5.1)$ & & $49.67 \%$ & $0.2[-0.58,0.98]$ \\
\hline Subtotal $* \star \star$ & 1008 & & 498 & & & $100 \%$ & $0.05[-0.5,0.6]$ \\
\hline \multicolumn{8}{|c|}{ Heterogeneity: $\mathrm{Tau}^{2}=0 ; \mathrm{Chi}^{2}=0.28, \mathrm{df}=1(\mathrm{P}=0.59) ; \mathrm{I}^{2}=0 \%$} \\
\hline \multicolumn{8}{|c|}{ Test for overall effect: $Z=0.17(P=0.86)$} \\
\hline \multicolumn{8}{|c|}{ 1.2.4 12 weeks (short-term) } \\
\hline Williams 2014 & 504 & $2.4(4.7)$ & 252 & $2.4(4.5)$ & & $50.57 \%$ & $0[-0.69,0.69]$ \\
\hline Williams 2014 & 514 & $2.6(4.9)$ & 252 & $2.4(4.5)$ & & $49.43 \%$ & $0.2[-0.5,0.9]$ \\
\hline 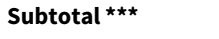 & 1018 & & 504 & & & $100 \%$ & $0.1[-0.39,0.59]$ \\
\hline \multicolumn{8}{|c|}{ Heterogeneity: $\operatorname{Tau}^{2}=0 ; \mathrm{Chi}^{2}=0.16, \mathrm{df}=1(\mathrm{P}=0.69) ; \mathrm{I}^{2}=0 \%$} \\
\hline \multicolumn{8}{|c|}{ Test for overall effect: $\mathrm{Z}=0.39(\mathrm{P}=0.69)$} \\
\hline
\end{tabular}

\section{Analysis 1.3. Comparison 1 Acute low back pain - paracetamol versus placebo, Outcome 3 Quality of life, physical component.}

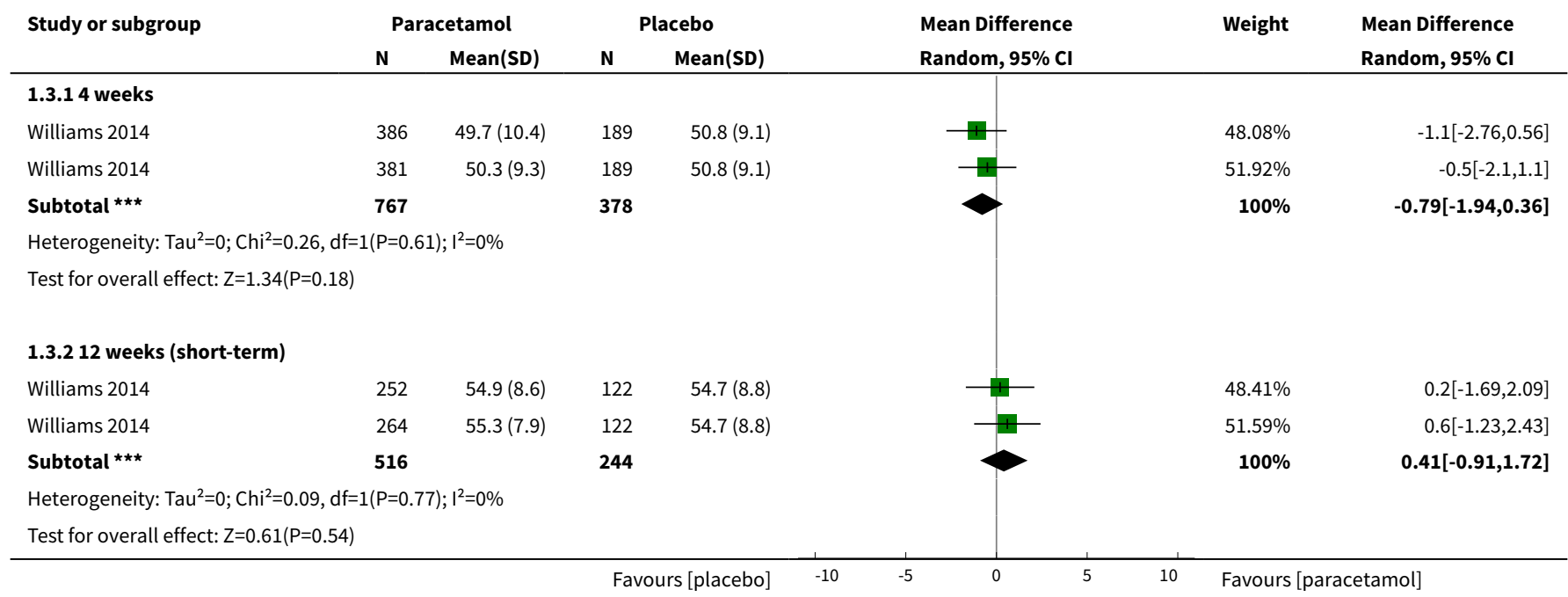


Analysis 1.4. Comparison 1 Acute low back pain - paracetamol versus placebo, Outcome 4 Quality of life, mental component.

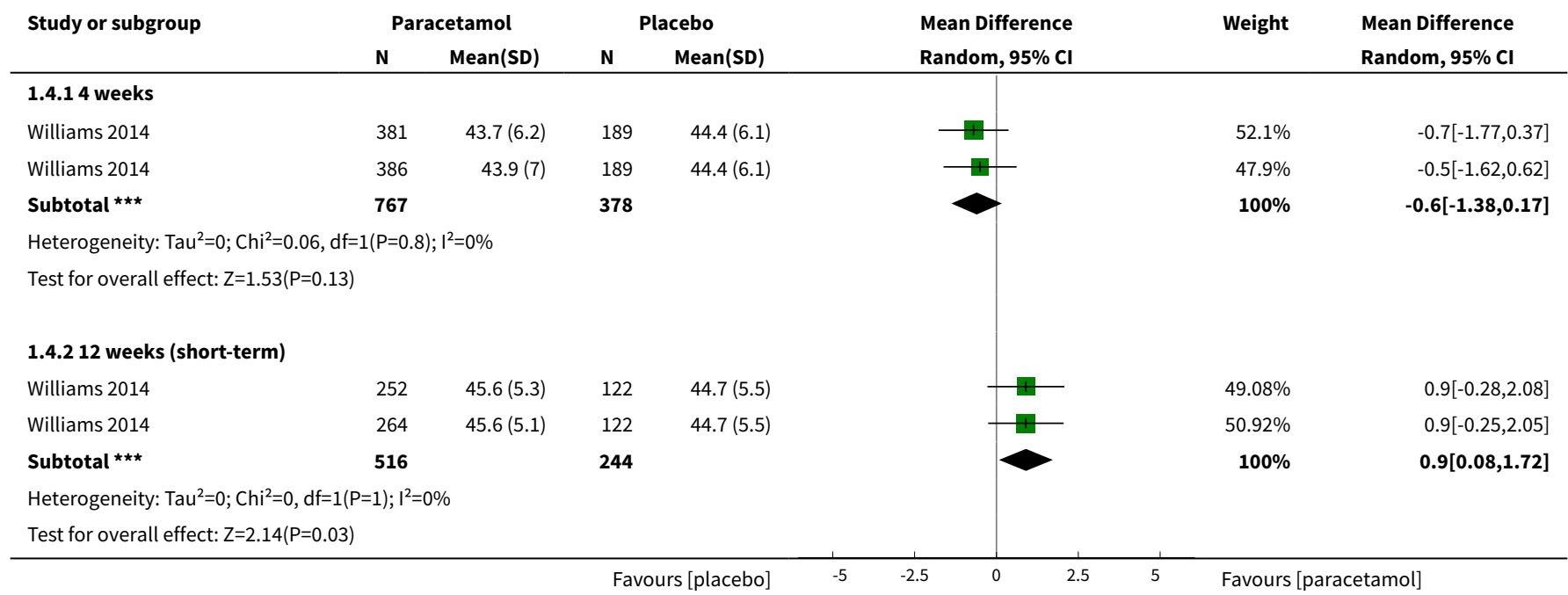

Analysis 1.5. Comparison 1 Acute low back pain - paracetamol versus placebo, Outcome 5 Function.

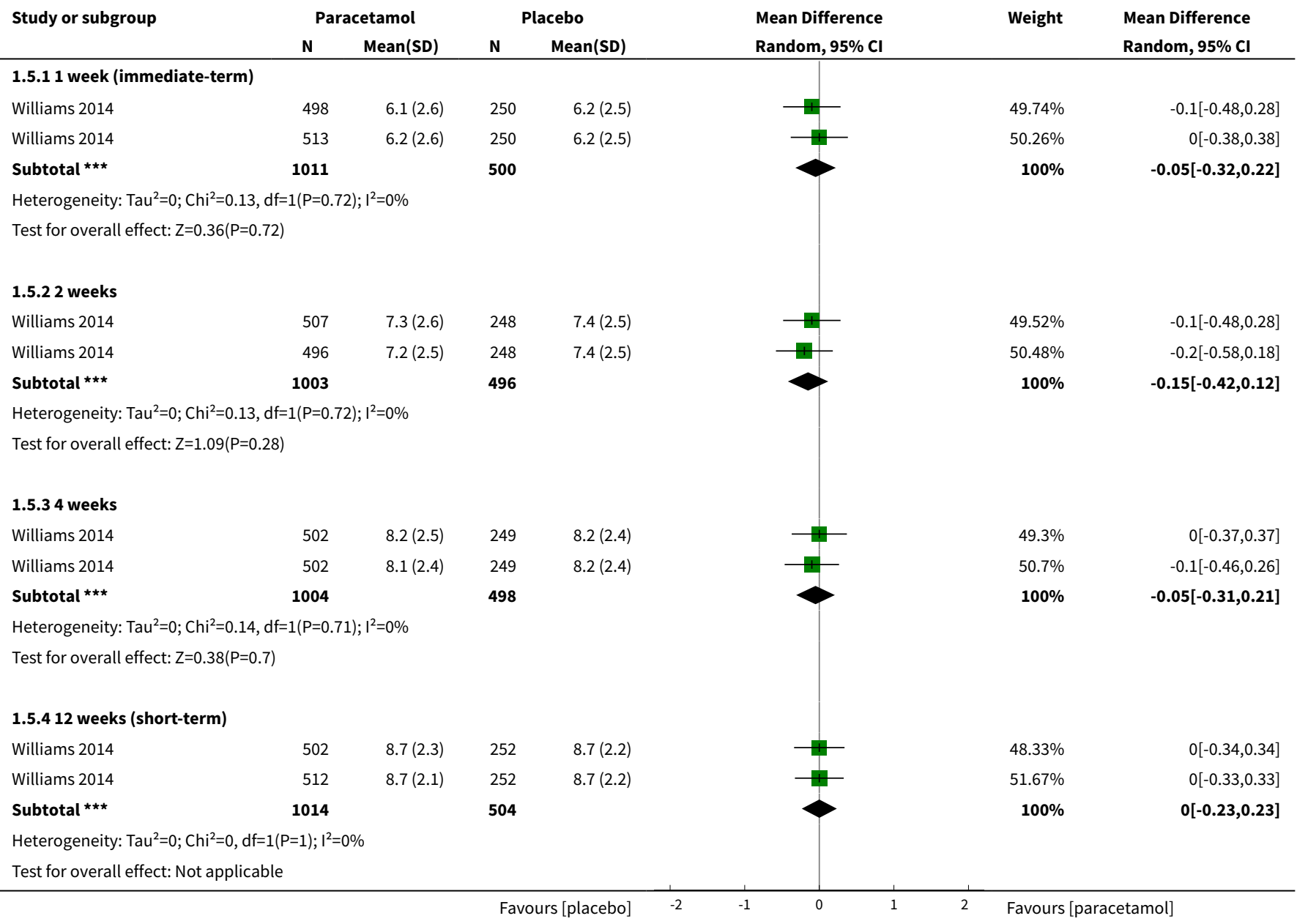


Analysis 1.6. Comparison 1 Acute low back pain - paracetamol versus placebo, Outcome 6 Adverse events.

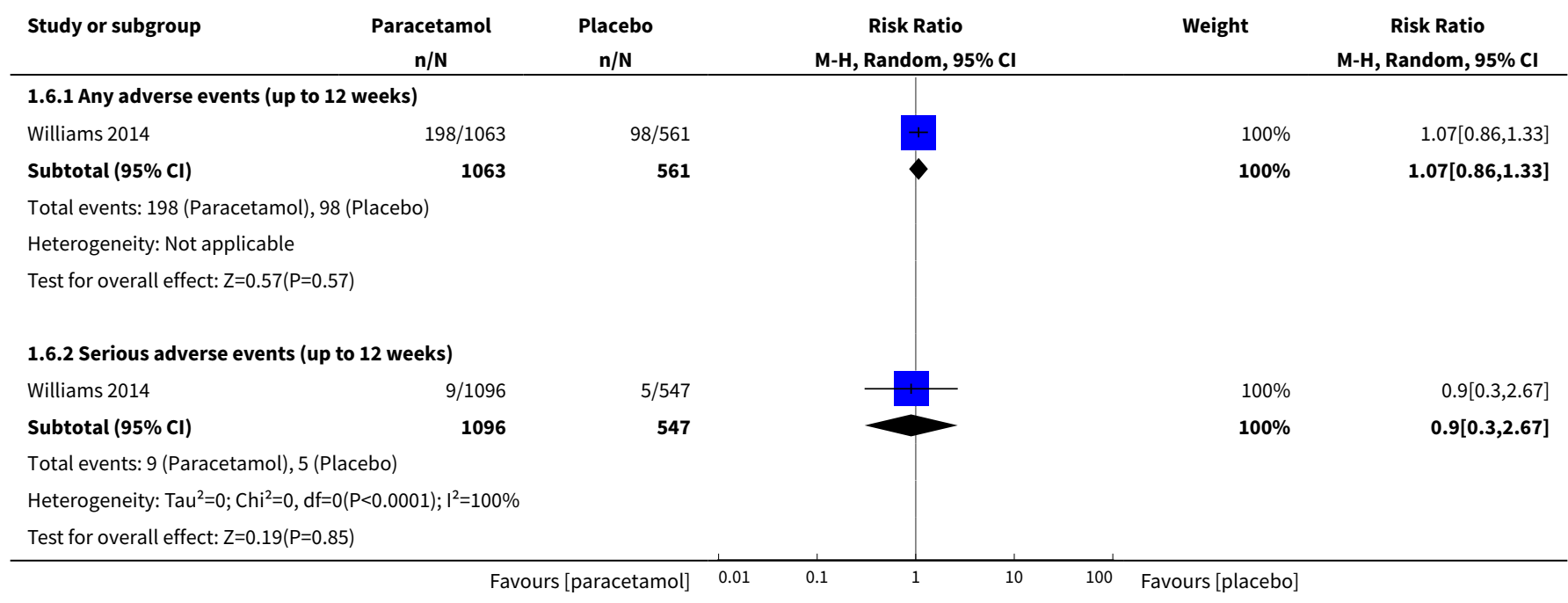

\section{Analysis 1.7. Comparison 1 Acute low back pain - paracetamol versus placebo, Outcome $7 \mathrm{Global}$ impression of recovery.}

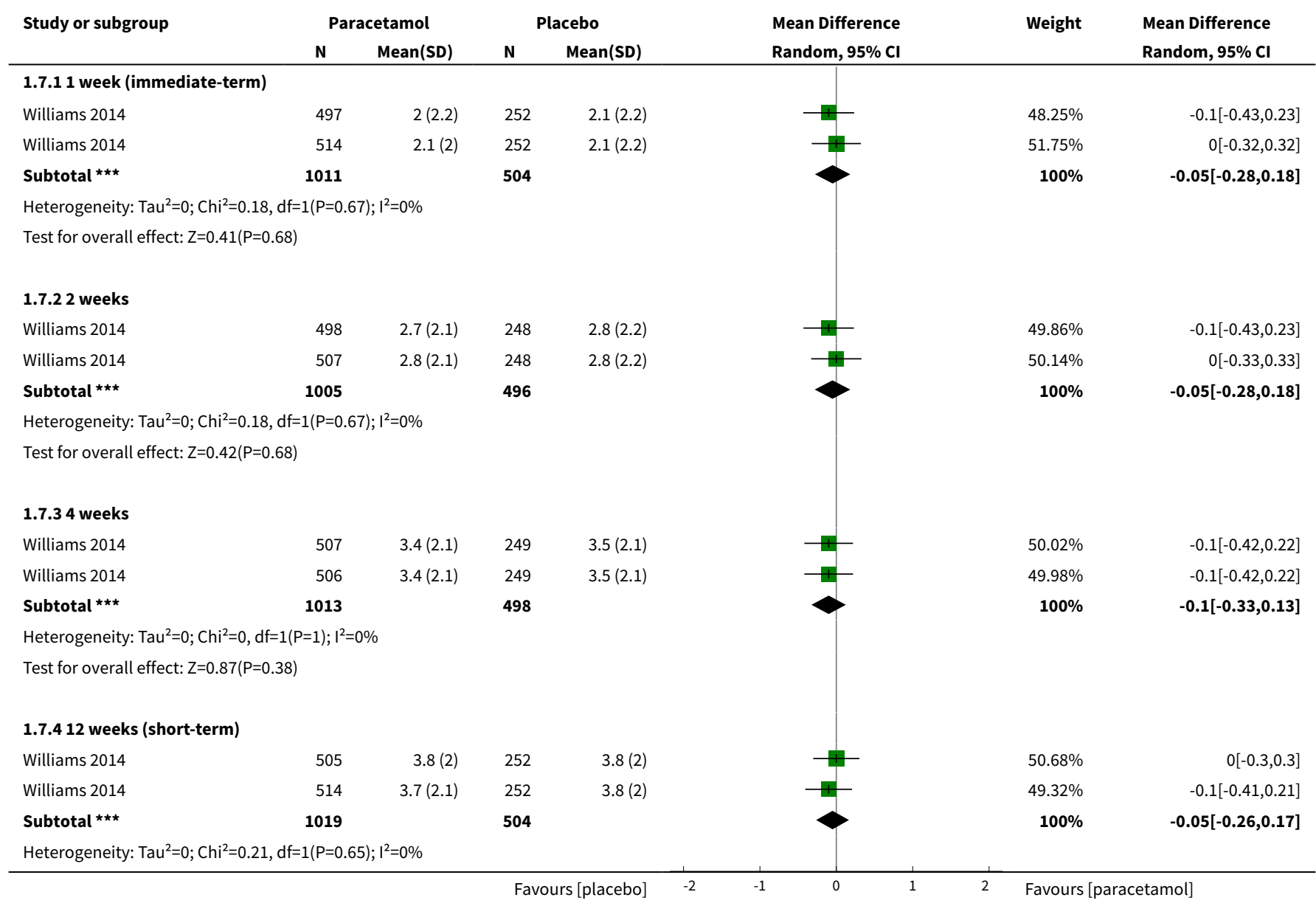




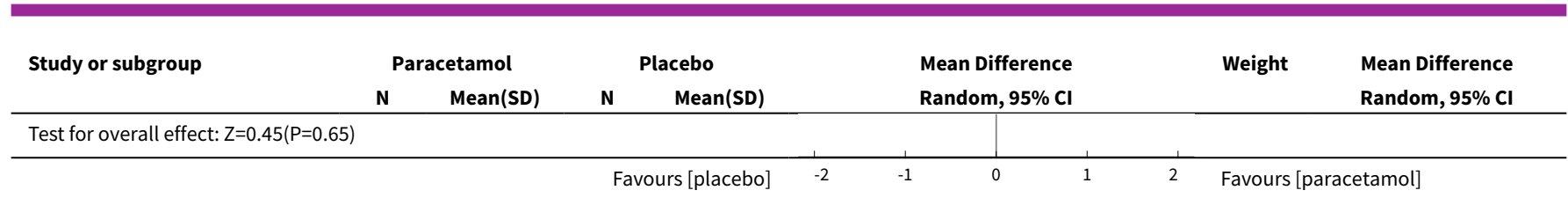

Analysis 1.8. Comparison 1 Acute low back pain - paracetamol versus placebo, Outcome 8 Poor sleep quality.

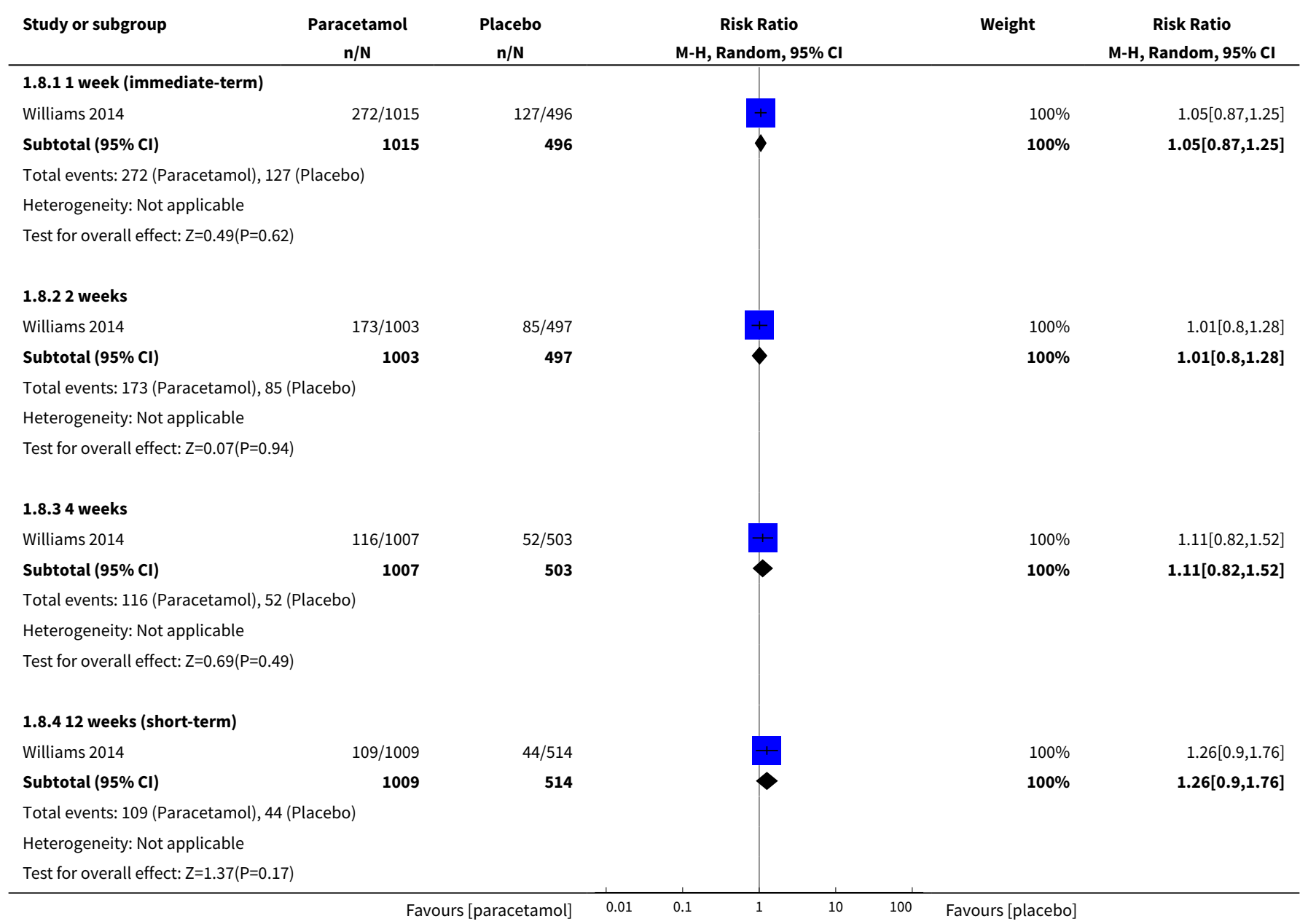

\section{Analysis 1.9. Comparison 1 Acute low back pain - paracetamol versus placebo, Outcome 9 Patient adherence.}

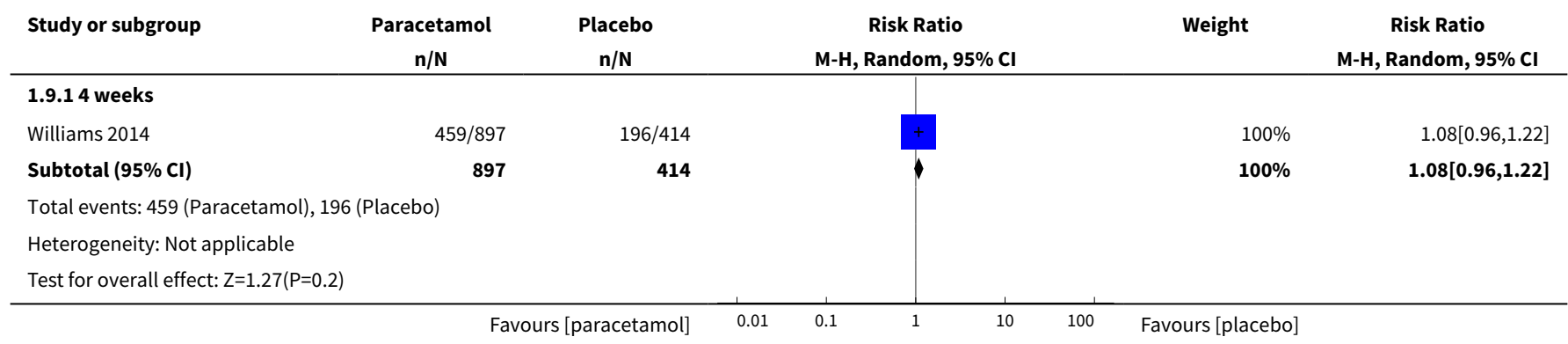


Analysis 1.10. Comparison 1 Acute low back pain - paracetamol versus placebo, Outcome 10 Use of rescue medication.

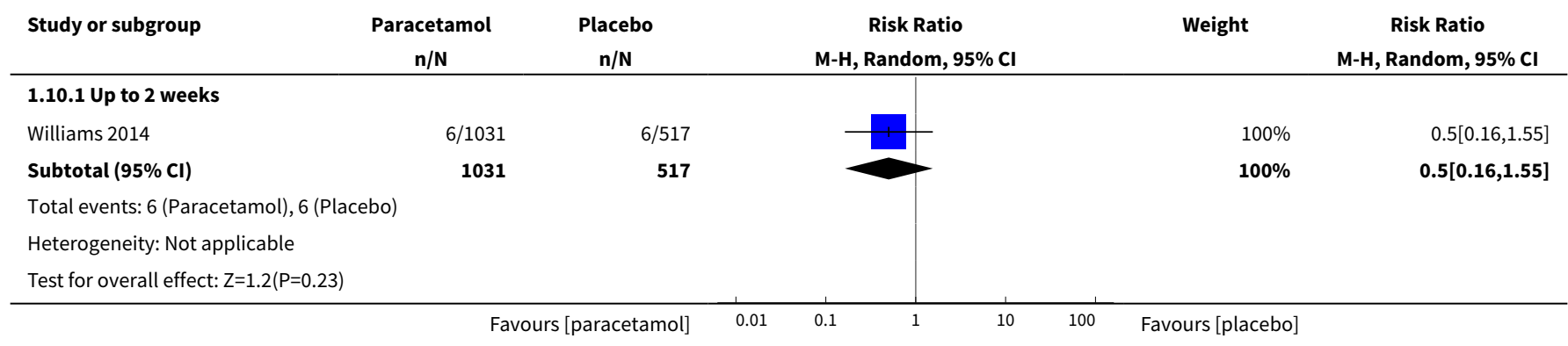

\section{AP PEN DICES}

\section{Appendix 1. CENTRAL search strategy}

Last searched 07 August 2015

1. acetaminophen.mp. or exp Acetaminophen/

2. Analgesics, Non-Narcotic/tu [Therapeutic Use]

3. (paracetamol or tylenol or panadol).mp.

4. 1 or 2 or 3

5. exp Osteoarthritis, Hip/ or exp Osteoarthritis/ or exp Osteoarthritis, Spine/ or exp Osteoarthritis, Knee/

6. Low back pain.mp. or exp Low Back Pain/

7. Neck pain.mp. or exp Neck Pain/

8. ("low back pain" or "back pain" or "neck pain" or backache or lumbago or "neck ache" or "spin* pain" or "knee pain" or "hip pain").mp.

\section{5 or 6 or 7 or 8}

10. 4 and 9

\section{Appendix 2. MEDLINE search strategy}

Last searched 07 August 2015

1. acetaminophen.mp. OR exp acetaminophen/

2. *Analgesics, Non-Narcotic/tu, th [Therapeutic Use, Therapy]

3. analgesic*.ab,ti.

4. (aceta OR actimin OR anacin OR apacet OR "aspirin free anacin" OR acamol OR acetalgin OR adol OR aldolOR OR alvedon OR apiretal OR atamel OR atasol OR benuron OR biogesic OR "biogesic kiddielets" OR buscapina OR banesin OR "ben u ron" OR calpol OR captin OR cemol OR coldex OR cotibin OR crocin OR dafalgan OR daleron OR "dawa ya magi" OR depon OR dexamol OR dolex OR dolgesic OR doliprane OR dolorol OR dolprone OR "duiyixian anjifen pian" OR dapa OR dolo OR datril OR duatrol OR dayquil OR efferalgan OR enelfa OR europain OR febrectal OR febricet OR febridol OR fensum OR feverall OR fibi OR "fibi plus" OR gelocatil OR gripin OR gesic OR genapap OR genebs OR hedex OR hedanol OR herron OR influbene OR kafa OR kitadol OR lekadol OR lupocet OR lemsip OR liquiprin OR pyrigesic OR mexalen OR milidon OR minoset OR momentum OR napa OR "neo kiddielets" OR neopap OR "oraphen pd" OR pyrigesic OR pacol OR pamol OR parol OR panado OR panadol OR panamax OR panda OR panodil OR pyrigesic OR paracet OR paracetamol OR paracitol OR paralen OR paramed OR paramol OR parol OR perdolan OR perfalgan OR pinex OR "pyongsu cetamol" OR pyrenol OR pyrigesic OR plicet OR panadrex OR paratabs OR paralgin OR phenaphen OR revanin OR rokamol OR rubophen OR redutemp OR sara OR scanol OR "sinpro n" OR "snaplets fr" OR suppap 
OR tachipirin OR tachipirina OR tafirol OR tapsin OR termalgin OR tempra OR thomapyrin OR tipol OR "togal classic duo" OR treuphadol OR triaminic OR tylenol OR tamen OR tapanol OR tipol OR uphamol OR vermidon OR vitamol OR valorin OR xumadol OR zolben).tw.

\section{OR/1-4}

6. osteoarthritis.mp. OR exp osteoarthritis/

7. exp low back pain/

8. exp back pain/

9. exp neck pain/

10. ("low back pain" OR "back pain" OR "neck pain" OR backache OR lumbago OR "neck ache" OR "spin* pain" OR "knee pain" OR "hip pain").mp.

11. OR/6-10

12. 5 AND 11

13. randomized controlled trial.pt. OR exp randomized controlled trial/

14. "randomized controlled trial".mp.

15. exp random allocation/

16. placebo.mp. OR exp placebos/OR exp placebo effect/

17. (random adj3 trial).ab,ti.

18. "controlled clinical trial".mp. OR exp controlled clinical trial/

19. Random*.ab,ti.

20. OR/13-19

21. 12 AND 20

22. limit 21 to humans

\section{Appendix 3. EMBASE search strategy}

Last searched 07 August 2015

1. 'acetaminophen'/exp OR 'acetaminophen'

2. (aceta OR actimin OR anacin OR apacet OR "aspirin free anacin" OR acamol OR acetalgin OR adol OR aldolOR OR alvedon OR apiretal OR atamel OR atasol OR benuron OR biogesic OR "biogesic kiddielets" OR buscapina OR banesin OR "ben u ron" OR calpol OR captin OR cemol OR coldex OR cotibin OR crocin OR dafalgan OR daleron OR "dawa ya magi" OR depon OR dexamol OR dolex OR dolgesic OR doliprane OR dolorol OR dolprone OR "duiyixian anjifen pian" OR dapa OR dolo OR datril OR duatrol OR dayquil OR efferalgan OR enelfa OR europain OR febrectal OR febricet OR febridol OR fensum OR feverall OR fibi OR "fibi plus" OR gelocatil OR gripin OR gesic OR genapap OR genebs OR hedex OR hedanol OR herron OR influbene OR kafa OR kitadol OR lekadol OR lupocet OR lemsip OR liquiprin OR pyrigesic OR mexalen OR milidon OR minoset OR momentum OR napa OR "neo kiddielets" OR neopap OR "oraphen pd" OR pyrigesic OR pacol OR pamol OR parol OR panado OR panadol OR panamax OR panda OR panodil OR pyrigesic OR paracet OR paracetamol OR paracitol OR paralen OR paramed OR paramol OR parol OR perdolan OR perfalgan OR pinex OR "pyongsu cetamol" OR pyrenol OR pyrigesic OR plicet OR panadrex OR paratabs OR paralgin OR phenaphen OR revanin OR rokamol OR rubophen OR redutemp OR sara OR scanol OR "sinpro n" OR "snaplets fr" OR suppap OR tachipirin OR tachipirina OR tafirol OR tapsin OR termalgin OR tempra OR thomapyrin OR tipol OR "togal classic duo" OR treuphadol OR triaminic OR tylenol OR tamen OR tapanol OR tipol OR uphamol OR vermidon OR vitamol OR valorin OR xumadol OR zolben)

\section{1 OR 2}

4. 'osteoarthritis'/exp OR 'osteoarthritis'

5. 'low back pain'/exp OR 'low back pain'

6. 'backache'/exp OR 'backache'

7. 'neck pain'/exp OR 'neck pain'

Paracetamol for low back pain (Review) 
8. 'low back pain' OR 'back pain' OR 'neck pain' OR backache OR lumbago OR 'neck ache' OR 'spin\$ pain' OR 'knee pain' OR 'hip pain' 9. OR (4-8)

\section{3 AND 9}

11. 'randomized controlled trial (topic)'/exp OR 'randomized controlled trial (topic)'

12. 'randomization'/exp OR 'randomization'

13. 'placebo'/exp OR 'placebo'

14. randomized:ab

15. placebo:ab

16. randomly:ab

17. OR (11-16)

18. 10 AND 17

\section{Appendix 4. CINAHL search strategy}

Last searched 07 August 2015

\section{S15. S7 AND S14}

S14. S8 OR S9 OR S10 OR S11 OR S12 OR S13

S13. "backache"

S12. "hip pain"

S11. (MH "Knee Pain+") OR "knee pain"

S10. (MH "Neck Pain") OR "neck pain"

S9. (MH "Low Back Pain") OR "low back pain" OR (MH "Back Pain+")

S8. (MH "Osteoarthritis+") OR "osteoarthritis" OR (MH "Osteoarthritis, Spine+") OR (MH "Osteoarthritis, Knee") OR (MH "Osteoarthritis, Hip")

S7. S1 OR S2 OR S3 OR S4 OR S5 OR S6

S6. "panadol"

S5. "tylenol"

S4. "paracetamol"

S3. "analgesic\$"

S2. (MH "Analgesics+/TU")

S1. (MH "Acetaminophen") OR "acetaminophen"

\section{Appendix 5. AMED search strategy}

Last searched 07 August 2015

1. exp Acetaminophen/ OR acetaminophen.mp.

2. exp Analgesics/ OR Analgesics.mp.

3. exp Drug therapy/ OR drug therapy.mp.

4. analgesic ${ }^{\star} . a b, t i$. 
5. (aceta OR actimin OR anacin OR apacet OR "aspirin free anacin" OR acamol OR acetalgin OR adol OR aldolor OR alvedon OR apiretal OR atamel OR atasol OR benuron OR biogesic OR "biogesic kiddielets" OR buscapina OR banesin OR "ben u ron" OR calpol OR captin OR cemol OR coldex OR cotibin OR crocin OR dafalgan OR daleron OR "dawa ya magi" OR depon OR dexamol OR dolex OR dolgesic OR doliprane OR dolorol OR dolprone OR "duiyixian anjifen pian" OR dapa OR dolo OR datril OR duatrol OR dayquil OR efferalgan OR enelfa OR europain OR febrectal OR febricet OR febridol OR fensum OR feverall OR fibi OR "fibi plus" OR gelocatil OR gripin OR gesic OR genapap OR genebs OR hedex OR hedanol OR herron OR influbene OR kafa OR kitadol OR lekadol OR lupocet OR lemsip OR liquiprin OR pyrigesic OR mexalen OR milidon OR minoset OR momentum OR napa OR "neo kiddielets" OR neopap OR "oraphen pd" OR pyrigesic OR pacol OR pamol OR parol OR panado OR panadol OR panamax OR panda OR panodil OR pyrigesic OR paracet OR paracetamol OR paracitol OR paralen OR paramed OR paramol OR parol OR perdolan OR perfalgan OR pinex OR "pyongsu cetamol" OR pyrenol OR pyrigesic OR plicet OR panadrex OR paratabs OR paralgin OR phenaphen OR revanin OR rokamol OR rubophen OR redutemp OR sara OR scanol OR "sinpro n" OR "snaplets fr" OR suppap OR tachipirin OR tachipirina OR tafirol OR tapsin OR termalgin OR tempra OR thomapyrin OR tipol OR "togal classic duo" OR treuphadol OR triaminic OR tylenol OR tamen OR tapanol OR tipol OR uphamol OR vermidon OR vitamol OR valorin OR xumadol OR zolben).tw.

\section{6. $\mathrm{OR} / 1-5$}

7. exp Osteoarthritis/ OR osteoarthritis.mp.

8. exp Low back pain/ OR low back pain.mp.

9. back pain.mp. OR exp Backache/

10. exp Neck pain/ OR neck pain.mp.

11. ("low back pain" OR "back pain" OR "neck pain" OR backache OR lumbago OR "neck ache" OR "spin^ pain" OR "knee pain" OR "hip pain").mp.

12. OR/7-11

13. 6 AND 12

14. exp Randomized controlled trials/ OR randomized controlled trial.mp.

15. randomized controlled trial.pt.

16. exp Random allocation/ OR random allocation.mp.

17. exp Placebos/ OR placebo.mp.

18. (random* adj3 trial).ab,ti.

19. Random.ab,ti.

20. OR/14-19

21. 13 AND 20

\section{Appendix 6. Web of Science search strategy}

Last searched 07 August 2015

16. \#15 AND \#9

Indexes=SCI-EXPANDED, SSCI, A\&HCI, CPCI-S, CPCI-SSH, CCR-EXPANDED, IC Timespan=All years

15. \#14 OR \#13 OR \#12 OR \#11 OR \#10

Indexes=SCI-EXPANDED, SSCI, A\&HCI, CPCI-S, CPCI-SSH, CCR-EXPANDED, IC Timespan=All years

14. TOPIC: $\left(\right.$ Random $\left.{ }^{\star}\right)$

Indexes=SCI-EXPANDED, SSCI, A\&HCI, CPCI-S, CPCI-SSH, CCR-EXPANDED, IC Timespan=All years

13. TOPIC: (controlled clinical trial)

Indexes=SCI-EXPANDED, SSCI, A\&HCI, CPCI-S, CPCI-SSH, CCR-EXPANDED, IC Timespan=All years

12. TOPIC: (placebo) 
Indexes=SCI-EXPANDED, SSCI, A\&HCI, CPCI-S, CPCI-SSH, CCR-EXPANDED, IC Timespan=All years

11. TOPIC: (random allocation)

Indexes=SCI-EXPANDED, SSCI, A\&HCl, CPCI-S, CPCI-SSH, CCR-EXPANDED, IC Timespan=All years

10. TOPIC: (randomized controlled trial)

Indexes=SCI-EXPANDED, SSCI, A\&HCI, CPCI-S, CPCI-SSH, CCR-EXPANDED, IC Timespan=All years

9. \#3 AND \#8

Indexes=SCI-EXPANDED, SSCI, A\&HCI, CPCI-S, CPCI-SSH, CCR-EXPANDED, IC Timespan=All years

8. \#7 OR \#6 OR \#5 OR \#4

Indexes=SCI-EXPANDED, SSCI, A\&HCI, CPCI-S, CPCI-SSH, CCR-EXPANDED, IC Timespan=All years

7. TOPIC: ((spin^ pain" OR "knee pain" OR "hip pain"))

Indexes=SCI-EXPANDED, SSCI, A\&HCI, CPCI-S, CPCI-SSH, CCR-EXPANDED, IC Timespan=All years

6. TOPIC: (neck pain)

Indexes=SCI-EXPANDED, SSCI, A\&HCI, CPCI-S, CPCI-SSH, CCR-EXPANDED, IC Timespan=All years

5. TOPIC: (back pain)

Indexes=SCI-EXPANDED, SSCI, A\&HCI, CPCI-S, CPCI-SSH, CCR-EXPANDED, IC Timespan=All years

4. TOPIC: (osteoarthritis)

Indexes=SCI-EXPANDED, SSCI, A\&HCI, CPCI-S, CPCI-SSH, CCR-EXPANDED, IC Timespan=All years

3. \#2 OR \#1

Indexes=SCI-EXPANDED, SSCI, A\&HCI, CPCI-S, CPCI-SSH, CCR-EXPANDED, IC Timespan=All years

2. TOPIC: (Paracetamol OR tylenol OR panadol)

Indexes=SCI-EXPANDED, SSCI, A\&HCI, CPCI-S, CPCI-SSH, CCR-EXPANDED, IC Timespan=All years

1. TOPIC: (acetaminophen)

Indexes=SCI-EXPANDED, SSCI, A\&HCI, CPCI-S, CPCI-SSH, CCR-EXPANDED, IC Timespan=All years

\section{Appendix 7. LILACS search strategy}

Last searched 07 August 2015

((Acetaminophen OR paracetamol OR tylenol OR panadol) AND (osteoarthritis OR back pain OR lumbago OR backache OR neck pain OR knee pain OR hip pain))

\section{Appendix 8. IPA search strategy}

Last searched 07 August 2015

1. acetaminophen.mp.

2. (aceta or actimin or anacin or apacet or "aspirin free anacin" or acamol or acetalgin or adol or aldolOR or alvedon or apiretal or atamel or atasol or benuron or biogesic or "biogesic kiddielets" or buscapina or banesin or "ben u ron" or calpol or captin or cemol or coldex or cotibin or crocin or dafalgan or daleron or "dawa ya magi" or depon or dexamol or dolex or dolgesic or doliprane or dolorol or dolprone or "duiyixian anjifen pian" or dapa or dolo or datril or duatrol or dayquil or efferalgan or enelfa or europain or febrectal or febricet or febridol or fensum or feverall or fibi or "fibi plus" or gelocatil or gripin or gesic or genapap or genebs or hedex or hedanol or herron or influbene or kafa or kitadol or lekadol or lupocet or lemsip or liquiprin or pyrigesic or mexalen or milidon or minoset or momentum or napa or "neo kiddielets" or neopap or "oraphen pd" or pyrigesic or pacol or pamol or parol or panado or panadol or panamax or panda or panodil or pyrigesic or paracet or paracetamol or paracitol or paralen or paramed or paramol or parol or perdolan or perfalgan or pinex or "pyongsu cetamol" or pyrenol or pyrigesic or plicet or panadrex or paratabs or paralgin or phenaphen or revanin or rokamol or rubophen 
or redutemp or sara or scanol or "sinpro $\mathrm{n}$ " or "snaplets fr" or suppap or tachipirin or tachipirina or tafirol or tapsin or termalgin or tempra or thomapyrin or tipol or "togal classic duo" or treuphadol or triaminic or tylenol or tamen or tapanol or tipol or uphamol or vermidon or vitamol or valorin or xumadol or zolben).tw.

\section{1 OR 2}

4. osteoarthritis.mp.

5. low back pain.mp.

6. back pain.mp.

7. neck pain.mp.

8. ("low back pain" or "back pain" or "neck pain" or backache or lumbago or "neck ache" or "spin* pain" or "knee pain" or "hip pain").mp.

9. $\mathrm{OR} / 4-8$

10. 3 AND 9

\section{Appendix 9. ClinicalTrials.gov and WHO ICTRP search strategy}

Last searched 07 August 2015

ClinicalTrials.gov: Search: (paracetamol OR acetaminophen) AND Condition: back pain

WHO ICTRP: Title: (paracetamol OR acetaminophen) AND Condition: back pain

\section{Appendix 10. 'Risk of bias' criteria}

\section{Random sequence generation (selection bias)}

\section{Selection bias (biased allocation to interventions) due to inadequate generation of a randomised sequence}

There is a low risk of selection bias if the investigators describe a random component in the sequence generation process such as: referring to a random number table, using a computer random number generator, coin tossing, shuffling cards or envelopes, throwing dice, drawing of lots, minimisation (minimisation may be implemented without a random element, and this is considered to be equivalent to being random).

There is a high risk of selection bias if the investigators describe a non-random component in the sequence generation process such as: sequence generated by odd or even date of birth, date (or day) of admission, hospital or clinic record number, or allocation by judgement of the clinician, preference of the participant, results of a laboratory test or a series of tests, or availability of the intervention.

\section{Allocation concealment (selection bias)}

\section{Selection bias (biased allocation to interventions) due to inadequate concealment of allocations prior to assignment}

There is a low risk of selection bias if the participants and investigators enrolling participants could not foresee assignment because one of the following, or an equivalent method, was used to conceal allocation: central allocation (including telephone, web-based, and pharmacycontrolled randomisation); sequentially numbered drug containers of identical appearance; or sequentially numbered, opaque, sealed envelopes.

There is a high risk of bias if participants or investigators enrolling participants could possibly foresee assignments and thus introduce selection bias, such as allocation based on: using an open random allocation schedule (for example a list of random numbers); assignment envelopes were used without appropriate safeguards (for example if envelopes were unsealed or non-opaque or not sequentially numbered); alternation or rotation; date of birth; case record number; or other explicitly unconcealed procedures.

\section{Blinding of participants and personnel (performance bias)}

Performance bias due to knowledge of the allocated interventions by participants or personnel/care providers during the study

There is a low risk of performance bias if blinding of participants or personnel was ensured and it was unlikely that the blinding could have been broken; or if there was no blinding or incomplete blinding, but the review authors judge that the outcome is not likely to be influenced by lack of blinding. 


\section{Blinding of outcome assessor (detection bias)}

\section{Detection bias due to knowledge of the allocated interventions by outcome assessors}

There is low risk of detection bias if the blinding of the outcome assessment was ensured and it was unlikely that the blinding could have been broken; or if there was no blinding or incomplete blinding, but the review authors judge that the outcome is not likely to be influenced by lack of blinding, or:

- for participant-reported outcomes in which the participant was the outcome assessor (e.g. pain, disability): there is a low risk of bias for outcome assessors if there is a low risk of bias for participant blinding (Boutron 2005);

- for outcome criteria that are clinical or therapeutic events that will be determined by the interaction between participants and care providers (e.g. co-interventions, length of hospitalisation, treatment failure), in which the care provider is the outcome assessor: there is a low risk of bias for outcome assessors if there is a low risk of bias for care providers (Boutron 2005);

- for outcome criteria that are assessed from data from medical forms: there is a low risk of bias if the treatment or adverse effects of the treatment could not be noticed in the extracted data (Boutron 2005).

\section{Incomplete outcome data (attrition bias)}

\section{Attrition bias due to amount, nature, or handling of incomplete outcome data}

There is a low risk of attrition bias if: there were no missing outcome data; reasons for missing outcome data were unlikely to be related to the true outcome (for survival data, censoring unlikely to be introducing bias); missing outcome data were balanced in numbers, with similar reasons for missing data across groups; for dichotomous outcome data, the proportion of missing outcomes compared with the observed event risk was not enough to have a clinically relevant impact on the intervention effect estimate; for continuous outcome data, the plausible effect size (difference in means or standardised difference in means) among missing outcomes was not enough to have a clinically relevant impact on observed effect size, or missing data were imputed using appropriate methods (if dropouts are very large, imputation using even 'acceptable' methods may still suggest a high risk of bias) (van Tulder 2003). The percentage of withdrawals and dropouts should not exceed $20 \%$ for short-term follow-up and $30 \%$ for long-term follow-up and should not lead to substantial bias (these percentages are commonly used but arbitrary, not supported by literature) (van Tulder 2003).

\section{Selective reporting (reporting bias)}

\section{Reporting bias due to selective outcome reporting}

There is a low risk of reporting bias if the study protocol is available and all of the study's prespecified (primary and secondary) outcomes that are of interest in the review have been reported in the prespecified way, or if the study protocol is not available but it is clear that the published reports include all expected outcomes, including those that were prespecified (convincing text of this nature may be uncommon).

There is a high risk of reporting bias if not all of the study's prespecified primary outcomes have been reported; one or more primary outcomes is reported using measurements, analysis methods, or subsets of the data (for example subscales) that were not prespecified; one or more reported primary outcomes were not prespecified (unless clear justification for their reporting is provided, such as an unexpected adverse effect); one or more outcomes of interest in the review are reported incompletely so that they cannot be entered in a meta-analysis; the study report fails to include results for a key outcome that would be expected to have been reported for such a study.

\section{Other bias}

\section{Bias due to problems not covered elsewhere in the table}

There is a low risk of bias if the study appears to be free of other sources of bias not addressed elsewhere (for example study funding).

\section{Appendix 11. The GRADE approach to evidence synthesis}

The quality of evidence will be categorised as follows:

- High $(\odot \odot \odot \odot)$ : further research is very unlikely to change the confidence in the estimate of effect.

- Moderate $(\odot \odot \odot))$ : further research is likely to have an important impact in the confidence in the estimate of effect.

- Low $(\odot \odot \circ)$ : further research is very likely to have an important impact on our confidence in the estimate of effect and is likely to change the estimate.

- Very Low $(\odot \circ \circ)$ ) : any estimate of effect is very uncertain.

The evidence available to answer each subquestion will be graded on the domains in the following manner: 


\section{Study design}

\section{Risk of bias}

Limitations in the study design and implementation may bias the estimates of the treatment effect. Our confidence in the estimate of the effect and in the following recommendation decreases if studies suffer from major limitations. We will examine all studies on five types of biases:

a) Selection (random sequence generation, allocation concealment, group similarities at baseline)

b) Performance (blinding of participants, blinding of healthcare providers)

c) Attrition (dropouts and intention-to-treat analysis)

d) Measurement (blinding of the outcome assessors and timing of outcome assessment)

e) Reporting bias (selective reporting)

\section{Inconsistency}

Inconsistency refers to an unexplained heterogeneity of results. Widely differing estimates of the treatment effect (i.e. heterogeneity or variability in results) across studies suggest true differences in underlying treatment effect. Inconsistency may arise from differences in: populations (e.g. drugs may have larger relative effects in sicker populations), interventions (e.g. larger effects with higher drug doses), or outcomes (e.g. diminishing treatment effect with time).

The quality of evidence will be downgraded as follows:

- by one level: when the heterogeneity or variability in results is large.

- by two levels: when the heterogeneity or variability in results is large AND there was inconsistency arising from populations, interventions, or outcomes.

\section{Indirectness}

Indirect population, intervention, comparator, or outcome: the question being addressed in this systematic review is different from the available evidence regarding the population, intervention, comparator, or an outcome in the included randomised trial.

The quality of evidence will be downgraded as follows:

- by one level: when there is indirectness in only one area

- by two levels: when there is indirectness in two or more areas

\section{Imprecision}

Results are imprecise when studies include relatively few participants and few events and thus have wide confidence intervals around the estimate of the effect. In such a case we judge the quality of the evidence to be lower than it otherwise would be because of uncertainty in the results. Each outcome is considered separately.

\section{For dichotomous outcomes}

We will consider imprecision for either of the following two reasons:

1. There is only one study (unless the study provide data from more than 300 participants). When there is more than one study, the total number of events is less than 300 (a threshold rule-of-thumb value) (Mueller 2007).

2. $95 \%$ confidence interval around the pooled or best estimate of effect includes both 1) no effect and 2) appreciable benefit or appreciable harm. The threshold for 'appreciable benefit' or 'appreciable harm' is a relative risk reduction (RRR) or relative risk increase (RRI) greater than $25 \%$.

The quality of the evidence will be downgraded as follows:

- by one level: when there is imprecision due to (1) or (2)

- by two levels: when there is imprecision due to (1) and (2)

\section{For continuous outcomes}

We will consider imprecision for either of the following two reasons: 
1. There is only one study (unless the study provide data from more than 400 participants). When there is more than one study, total population size is less than 400 (a threshold rule-of-thumb value; using the usual $\alpha$ and $\beta$, and an effect size of 0.2 standard deviations, representing a small effect).

2. $95 \%$ confidence interval includes no effect and the upper or lower confidence limit crosses an effect size (standardised mean difference) of 0.5 in either direction.

The quality of the evidence will be downgraded as follows:

- by one level: when there is imprecision due to (1) or (2)

- by two levels: when there is imprecision due to (1) and (2)

\section{Publication bias}

Publication bias is a systematic underestimate or an overestimate of the underlying beneficial or harmful effect due to the selective publication of studies.

The quality of evidence will be downgraded as follows:

- by one level: when the funnel plot suggests publication bias

\section{Magnitude of the effect}

8. Dose response gradient

\section{Influence of all plausible residual confounding}

\section{FEE D B A C K}

\section{From Andrew Miller, 24 November 2018}

\section{Summary}

In this manuscript [1], the authors performed a systematic review and meta-analysis of the effectiveness of paracetamol (aka acetaminophen) for non-specific low back pain (LBP) in which 3 randomized controlled trials (RCT) were included in the review (2 LBPAcute [2,3], 1 LBPChronic [4]), and two RCTs were included in the meta-analysis (1 LBPAcute [3], 1 LBPChronic [4]). There are significant limitations to this analysis that undermine the manuscript and invalidate the conclusions. The studies included in the meta-analysis assessed two different patient populations ( 1 acute, 1 chronic). Additionally, while one was a publication by one of the meta-analysis co-authors (CG Maher) [3], the other was a retracted study [4,5]. Dr. Kietaibl (formerly Kozek-Langenecker) did not consent to manuscript publication and demanded retraction after discovering deceptive practices by some co-authors that resulted in fraudulent data [5]. Moreover, Dr. Kietaibl was not contacted by the authors of this meta-analysis to determine the reasons for retraction. Including a retracted study in a metaanalysis means transferring major errors from a single study into the highest level of evidence, thereby compromising and invalidating the meta-analysis results. Moreover, excluding the retracted study would have prevented the performance of a meta-analysis at all. The results of this analysis are not valid, and readers should be cautioned against applying them in clinical practice.

Andrew Miller, East Carolina University, Associate Professor; Chief, Division of Research; Dept. Emergency Medicine

References

[1] Saragiotto BT, Machado GC, Ferreira ML, Pinheiro MB, Abdel Shaheed C, Maher CG. Paracetamol for low back pain. Cochrane Database Syst Rev 2016:CD012230.

[2] Nadler SF, Steiner DJ, Erasala GN, et al. Continuous low-level heat wrap therapy provides more efficacy than ibuprofen and acetaminophen for acute low back pain. Spine 2002;27:1012-7.

[3] Williams CM, Maher CG, Latimer J, et al. Efficacy of paracetamol for acute low-back pain: a double-blind, randomised controlled trial. Lancet 2014;384:1586-96.

[4] Wetzel L, Zadrazil M, Paternostro-Sluga T, Authried G, Kozek-Langenecker S, Scharbert G. Intravenous nonopioid analgesic drugs in chronic low back pain patients on chronic opioid treatment: A crossover, randomised, double-blinded, placebo-controlled study. Eur J Anaesthesiol 2014;31:35-40.

[5] [No Authors Listed]. Intravenous non opioid analgesic drugs in chronic low back pain patients on chronic opioid treatment: A crossover, randomised, double-blinded, placebo-controlled study: Retraction. Eur J Anaesthesiol 2015;31:287.

\section{Reply}

We welcome Dr. Miller's comments. However, one of his criticisms seems exaggerated. He suggested that our inclusion of the retracted study by Wetzel et al. invalidates the review. This is not the case. This study contributed to only one treatment comparison, one involving 
"very low quality" evidence. The inclusion or deletion of this one study from our meta-analysis will not change the key message of the review.

To clarify our procedures, it is important to mention that we attempted to contact the authors of the retracted study a couple of times with no success. Then we notified the Cochrane Back and Neck Group prior to the inclusion of the paper and acknowledged the retracted study in the review. The retraction notice from European Journal of Anaesthesiology states that the reason for retracting was because one author did not consent to the publication, with no mention of fraudulent data as Dr Miller asserts.

Nevertheless, after discussing this issue with the Editors of the Cochrane Back \& Neck Group and with upcoming guidance from the Editorial and Methods Department, our decision is to exclude the study from the review.

\section{Contributors}

Bruno T Saragiotto, Gustavo C Machado and Chris G Maher

WHAT'S NEW

\begin{tabular}{lll}
\hline Date & Event & Description \\
\hline 16 January 2019 & Feedback has been incorporated & $\begin{array}{l}\text { Feedback received November 2018. Response added January } \\
\text { 2019. See Feedback section. }\end{array}$ \\
\hline
\end{tabular}

\section{H I S T O R Y}

Review first published: Issue 6, 2016

\begin{tabular}{lll}
\hline Date & Event & Description \\
\hline 15 December 2016 & Amended & $\begin{array}{l}\text { Minor correction in the summary of findings table (correspond- } \\
\text { ing risk for serious adverse events) }\end{array}$ \\
\hline
\end{tabular}

\section{CONTRIBUTIONSOF AUTHORS}

Conception, design, data collection, analysis, and drafting of the protocol and previous review: Gustavo C Machado, Manuela L Ferreira, Marina B Pinheiro, and Christopher G Maher.

Update and adaptation for Cochrane review: Bruno T Saragiotto, Christina Abdel Shaheed, and Christopher G Maher.

Collection and assembly of data for the Cochrane review: Bruno T Saragiotto, Christina Abdel Shaheed, Marina B Pinheiro, and Gustavo C Machado.

Critical revision of the updated review for important intellectual content: Gustavo C Machado, Manuela L Ferreira, Christina Abdel Shaheed, and Christopher G Maher.

Drafting of the review: Bruno T Saragiotto and Christopher G Maher.

Final approval of the review: all authors.

\section{DECLARATIONSOF INTEREST}

Bruno T Saragiotto: No relevant interests.

Gustavo C Machado: No relevant interests.

Manuela L Ferreira: No relevant interests.

Marina B Pinheiro: No relevant interests. 
Christina Abdel Shaheed: No relevant interests.

Christopher G Maher is an author of the PACE trial, which was included in this review, however he did not participate in the 'Risk of bias' assessment or data extraction in this review. PACE was an investigator-initiated trial, funded by the National Health and Medical Research Council of Australia and GlaxoSmithKline (a manufacturer of paracetamol).

\section{SOURCES OF SUPPORT}

\section{Internal sources}

- None, Other.

\section{External sources}

- None, Other.

\section{DIFFERENCES BETWEEN PROTOCOLANDREVIEW}

This is an update of a review published in the BMJ (Machado 2015). The study protocol was previously registered on PROSPERO (registration number CRD42013006367). We followed the new recommendations of the Cochrane Back and Neck Group in this review (Furlan 2015), which was not stated in the protocol or previous version of this review as it was not yet published. However, there were no substantial changes from the protocol or the previous version of this review.

\section{INDEX TERMS}

\section{Medical Subject Headings (MeSH)}

Acetaminophen [ ${ }^{\star}$ therapeutic use]; Analgesics, Non-Narcotic [ ${ }^{*}$ therapeutic use]; Low Back Pain [ ${ }^{\star}$ drug therapy]; Randomized Controlled Trials as Topic; Treatment Outcome

\section{MeSH check words}

Humans; Middle Aged 